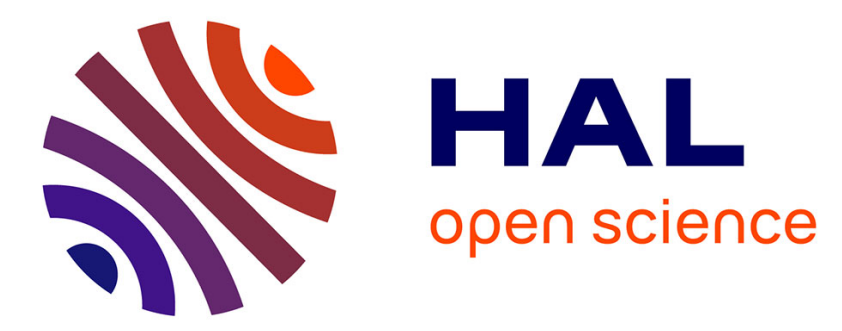

\title{
Pd-catalyzed intermolecular dehydrogenative Heck reactions of six membered heteroarenes
}

\author{
Jean Le Bras, Jacques Muzart
}

\section{To cite this version:}

Jean Le Bras, Jacques Muzart. Pd-catalyzed intermolecular dehydrogenative Heck reactions of six membered heteroarenes. Current Organic Chemistry, 2021, 25 (18), 10.2174/1385272825666210412160959 . hal-03373916

\section{HAL Id: hal-03373916 https://hal.science/hal-03373916}

Submitted on 11 Oct 2021

HAL is a multi-disciplinary open access archive for the deposit and dissemination of scientific research documents, whether they are published or not. The documents may come from teaching and research institutions in France or abroad, or from public or private research centers.
L'archive ouverte pluridisciplinaire HAL, est destinée au dépôt et à la diffusion de documents scientifiques de niveau recherche, publiés ou non, émanant des établissements d'enseignement et de recherche français ou étrangers, des laboratoires publics ou privés. 


\section{Pd-catalyzed intermolecular dehydrogenative Heck reactions of six membered heteroarenes}

Jean Le Bras and Jacques Muzart*

Institut de Chimie Moléculaire de Reims, UMR 7312, CNRS - Université de Reims Champagne-Ardenne, B.P. 1039, 51687 Reims Cedex 2, France

e-mail: jacques.muzart@univ-reims.fr

Jean Le Bras, ORCID: 0000-0003-2453-0949

Jacques Muzart, ORCID: 0000-0002-1276-4206

\section{Graphical abstract.}

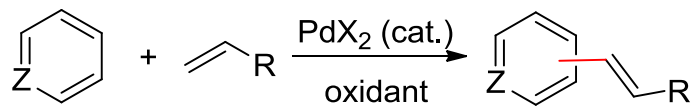

An update of the Pd-catalyzed cross-couplings of six-membered heteroarenes with alkenes, and the plausible mechanisms.

Abstract: The $\mathrm{Pd}^{\mathrm{II}}$-mediated cross-coupling of (hetero)arenes with alkenes may be an effective method for the formation of a C-C bond from two C-H bonds. Discovered by Fujiwara and co-workers in 1967, this reaction led to a number of reports that we firstly highlighted in 2011 (review with references till June 2010) and for which, we retained the name "dehydrogenative Heck reaction" (DHR). The DHR of six-membered heteroarenes, has been the subject of intensive research over the last ten years. The present review is limited to these dehydrogenative Heck reactions published since 2010, underlining the diversity of the procedures and, with personal comments, the mechanisms and intermediates that have been proposed.

Keywords: palladium; heteroarene; dehydrogenative Heck reaction; cross-coupling; C-H activation; alkenylation; catalysis.

\section{Introduction}

Palladium-catalyzed $\mathrm{C}-\mathrm{H}$ functionalization offers a broad range of transformations and has been at the forefront of organic synthesis over the last half-century [1]. In late sixties, Fujiwara's team disclosed the $\mathrm{Pd}^{\mathrm{II}}$ mediated synthesis of stilbene from the cross-coupling of styrene with benzene [2]. This formation of a $\mathrm{C}-\mathrm{C}$ bond from the coupling of two $\mathrm{C}-\mathrm{H}$ bonds is a powerful alternative to the traditional Pd-catalyzed procedure independently discovered by the teams of Mizoroki, Julia and Heck [3] ${ }^{1}$, which requires phenyl halide instead of benzene. Any prefunctionalization being required, the Fujiwara process has been the subject of intensive research leading to various efficient $\mathrm{Pd}^{\mathrm{II}}$-catalyzed couplings of (hetero)aromatic substrates with alkenes. We earlier reviewed the corresponding literature with references until June 2010 [4] using the term "Dehydrogenative Heck Reactions" (DHRs), initially proposed by Stoltz [5], to name such reactions which eliminate two $\mathrm{H}$ atoms and occur via an arylpalladium ${ }^{\mathrm{II}}$ intermediate. Recently, we reviewed the DHRs of five membered heteroarenes reported over the last ten years [6]. We now highlight the DHRs of six membered heteroarenes published during the same period [7]. As for our recent review, the reactions of fused bicyclic arenes which do not involve the $\mathrm{C}-\mathrm{H}$ bond of the hetero ring [8], as well those involving cross-coupling with another arene [9] will be discarded. The framework of the text depends on the nature of the aromatic substrate.

$\mathrm{Pd}^{\mathrm{II}}$-mediated activation of a $\mathrm{C}-\mathrm{H}$ bond of the heteroarene leading to heteroarylpalladium intermediate $\mathbf{1 A}$ is usually admitted as the key step of the DHR (Scheme 1, arene activation). Addition of $\mathbf{1 A}$ to the alkene gives 1B. Subsequent $\beta-\mathrm{H}$ elimination delivers the cross-coupling product and $\mathrm{Pd}^{0}$, the latter being regenerated into active $\mathrm{Pd}^{\mathrm{II}}$ species with an oxidant. Another mechanism involves the $\eta^{2}$-palladium complex $\mathbf{1 C}$ and its nucleophilic attack by the arene leading to $\mathbf{1 B}$ (Scheme 1, alkene activation). Both catalytic cycles describe

\footnotetext{
${ }^{1}$ The Mizoroki publication, submitted on October, 20, 1970, was cited by Heck's team which submitted their report on January, 13, 1972. On January 12, 1971, Julia's team deposited a "Pli cacheté", i.e. a sealed envelope, to the Société Chimique de France, which was open on May, 5, 1973.
} 
dehydrogenative cross-coupling reactions, but a reaction via the alkene complex cannot be named DHR. Broggini's team proposed the term "alkene activation" [10]. Actually, coordination of the alkene to palladium decreased the electron-density of the double bond, leading to its activation towards nucleophilic attack, that is a Friedel-Crafts reaction. According to ESI-MS [11], NMR [12] and kinetic isotope effect [13] studies, most dehydrogenative cross-coupling reactions would occur via the arene activation process. The site-selectivity of heteroarenes is governed by the "innate" or "guided" $\mathrm{C}-\mathrm{H}$ bond activation [14]. The former relies on the electronic properties of the heterocycle induced by the heteroatom [15], whereas the latter is relevant to either a directing group or a specific additive.

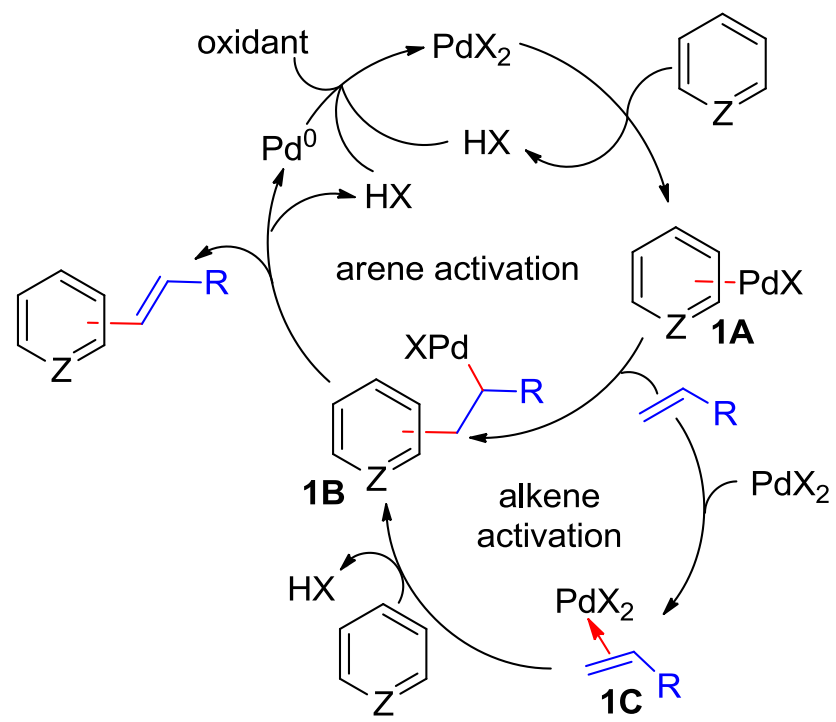

Scheme 1. Catalytic cycles of dehydrogenative cross-coupling reactions.

\section{2. $\mathbf{N}$-arenes}

\subsection{Pyridines}

Pyridine (py) is often used as base [16] or ligand [17] of DHRs [4], hence the difficulty to carry out its DHR. The first report, published in 2011, is due to Yu's team [13]. Treating a 16:1 mixture of pyridine and ethyl acrylate with $\mathrm{Pd}(\mathrm{OAc})_{2}\left(0.1\right.$ equiv.) and $\mathrm{Ag}_{2} \mathrm{CO}_{3}$ (0.5 equiv.) in $\mathrm{DMF}$ at $140{ }^{\circ} \mathrm{C}$ under air atmosphere provided $21 \%$ of ethyl pyridinylacrylates, the $\mathrm{C} 3$ substituted product being the main isomer (Eq. 1). The authors suspected that the low yield was due to strong coordination of the pyridine $\mathrm{N}$ atom to $\mathrm{Pd}^{\mathrm{II}}$, preventing interaction of the catalyst with the $\mathrm{C}-\mathrm{H}$ bonds of pyridine. Thus, they presumed that use of bidentate pyridyl ligands would favor the interaction of $\mathrm{Pd}^{\mathrm{II}}$ with the $\pi$-ring. As expected, the yield increased to $50 \%$ with 2,2'-bipyridine, and after extensive ligand screening, to $87 \%$ with 1,10-phenanthroline (Eq. 1). Switching to $\mathrm{O}_{2}$ instead of air atmosphere allowed to reduce the $\mathrm{Ag}_{2} \mathrm{CO}_{3}$ amount but with slight yield decrease. The $\mathrm{Pd}(\mathrm{OAc})_{2} / \mathrm{Ag}_{2} \mathrm{CO}_{3} /$ air procedure was used for the selective 3 -alkenylation (27-73\% yield) of various pyridines with acrylates, $\mathrm{N}, \mathrm{N}$ -

dimethylacrylamide, styrene and 2-vinyl-1,3-dioxolane (19 examples). Lower yields $(\approx 15 \%)$ were obtained with internal olefins. The team performed kinetic isotope effect $(\mathrm{KIE}=4)$ studies and proposed a mechanism that involves the arene activation. 


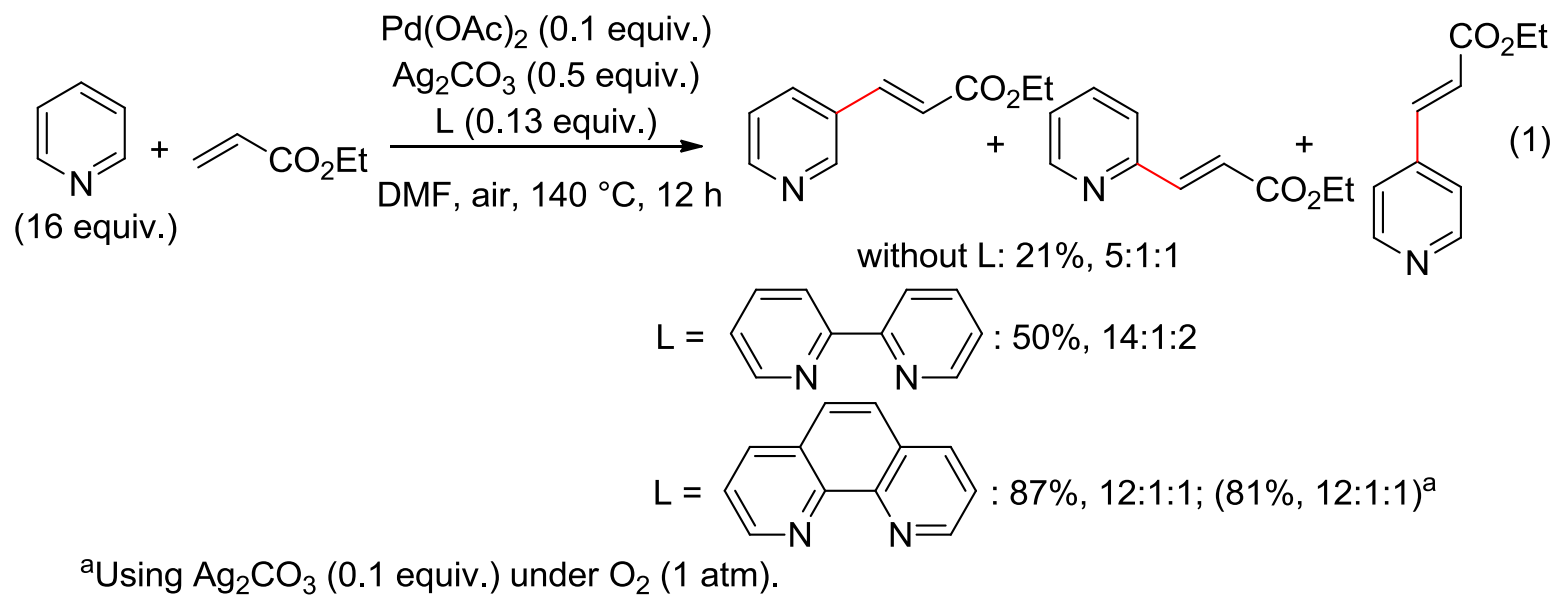

Selective $\mathrm{C} 2$ olefination was reported in 2012 by the teams of Ma and Huang using $\mathrm{Pd}(\mathrm{OAc})_{2}$ catalysis, $\mathrm{AgOAc}, \mathrm{O}_{2}$ and pivalic acid in DMF at $140{ }^{\circ} \mathrm{C}$ [18]. Yields and selectivities were tightly dependent on the pyridine:olefin:AgOAc:pivalic acid ratio, best results being with the 8:1:6:5 ratio leading in most cases to fair results (Eq. 2). Use of $\mathrm{Ag}_{2} \mathrm{CO}_{3}$ instead of $\mathrm{AgOAc}$ seems to be prejudicial to the selectivity but the reagents ratio was different (Eq. 2). Cross-coupling with an internal olefin such as butyl but-2-enoate did not occur. Pyridines with halogens atoms in both $\mathrm{C} 3$ and $\mathrm{C} 5$ positions afforded selective $\mathrm{C} 4$ olefination (Eq. 3). The authors determined a KIE identic to that observed by Yu's team $\left(k_{\mathrm{H}} / k_{\mathrm{D}}=4\right)$, and assumed a mechanism with $\mathrm{Pd}(\mathrm{OAc})_{2}$ as the catalytic species.

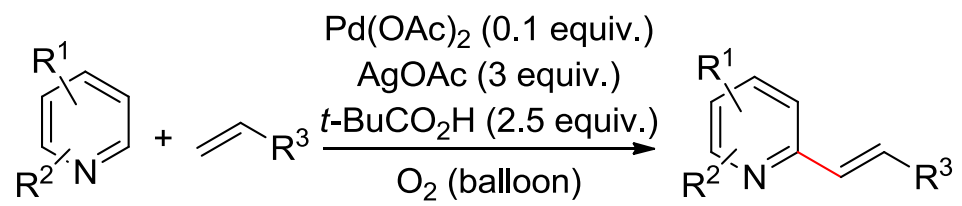

(8 equiv.) DMF, $140{ }^{\circ} \mathrm{C}, 20 \mathrm{~h}$

$\mathrm{R}^{1}, \mathrm{R}^{2}=\mathrm{H}, \mathrm{Me}, \mathrm{OMe}, \mathrm{Br}, \mathrm{Cl}, \mathrm{F}, \mathrm{CN}, \mathrm{NO}_{2}, \mathrm{CO}_{2} \mathrm{Me} ; \mathrm{R}^{3}=\mathrm{COBu}$, $\mathrm{CO}_{2} \mathrm{Et}, \mathrm{CO}_{2} \mathrm{Bu}, \mathrm{CONH}_{2}$, Ph; 20 examples: trace- $78 \%$ yield

$\mathrm{R}^{1}=\mathrm{R}^{2}=\mathrm{H}, \mathrm{R}^{3}=\mathrm{CO}_{2} \mathrm{Bu}: 61 \% \mathrm{a}, \mathrm{b}, \mathrm{c}, \mathrm{d}, \mathrm{e}$

aplus $\mathrm{C}-3$ substituted product ( $8 \%$ )

${ }^{\mathrm{b}} 34 \%$ with $\mathrm{AcOH}$ instead of $t-\mathrm{BuCO}_{2} \mathrm{H}$

'With pyridine (4 equiv.): $43 \%$ plus $\mathrm{C}-3$ substituted product (5\%)

${ }^{d}$ With pyridine (4 equiv.) and $t-\mathrm{BuCO}_{2} \mathrm{H}$ (1 equiv.): $27 \%$ plus $\mathrm{C}-3$ substituted product $(9 \%)$

eWith pyridine (4 equiv.), $t-\mathrm{BuCO}_{2} \mathrm{H}$ (1 equiv.) and $\mathrm{Ag}_{2} \mathrm{CO}_{3}$ (1.5 equiv.) instead of AgOAc: $17 \%$ plus $\mathrm{C}-3$ substituted product (15\%).

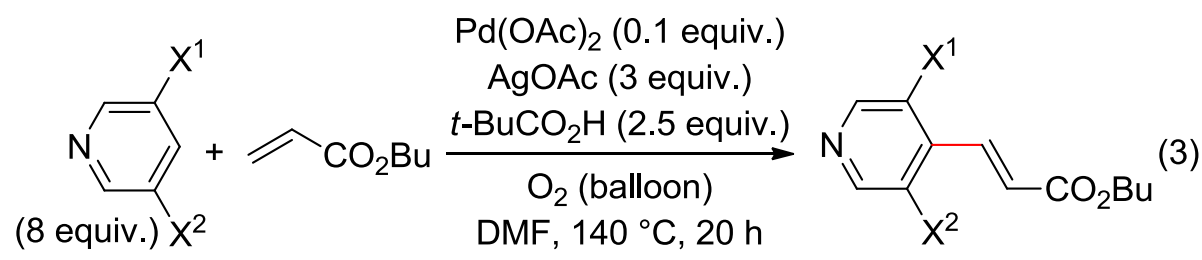

$$
\mathrm{X}^{1}=\mathrm{X}^{2}=\mathrm{F}: 70 \% ; \mathrm{X}^{1}=\mathrm{X}^{2}=\mathrm{Cl}: 68 \% ; \mathrm{X}^{1}=\mathrm{Br}, \mathrm{X}^{2}=\mathrm{F}: 60 \%
$$

The yield decrease of the pyridine/butyl acrylate reaction using $\mathrm{AcOH}$ instead of $t-\mathrm{BuCO}_{2} \mathrm{H}$ and the selectivity dependence on the amount of $t-\mathrm{BuCO}_{2} \mathrm{H}$ (Eq. 2) led us to suspect the involvement of $\mathrm{Pd}(\mathrm{OCO} t-\mathrm{Bu})_{2}$ $[19,20]$ or $\mathrm{Pd}(\mathrm{OCO} t-\mathrm{Bu})(\mathrm{OAc})$. Consequently, we retain a catalytic cycle mediated by $\mathrm{Pd}(\mathrm{OCOR})_{2}(\mathrm{R}=\mathrm{Me}$ or $t$ - 
$\mathrm{Bu}$ ) (Scheme 2). N-coordination of pyridine to $\mathrm{Pd}(\mathrm{OCOR})_{2}$ provides $\mathbf{2 A}$ which changes into $\mathbf{2 B}$ due to a strong trans-effect [21] of pyridine ligand. In their above report [13], Yu's team also called upon the "trans-effect" for the 2A to 2B step and cited the same references [21], but did not really refer to such phenomena in a subsequent review [22]. Insertion of palladium into $\mathrm{C} 2-\mathrm{H}$ or $\mathrm{C} 3-\mathrm{H}$ bond of pyridine leads to $\mathbf{2 C}$ and $\mathbf{2 C}$ ', respectively.

Ligand exchange followed by insertion of the $\mathrm{C}=\mathrm{C}$ bond into the pyridinylpalladium bond affords $2 \mathrm{D}$ from $2 \mathrm{C}$. Then, $\beta$-H elimination gives the $\mathrm{C} 2$ olefinated product. A similar pathway provides the minor product from $\mathbf{2}$ ',

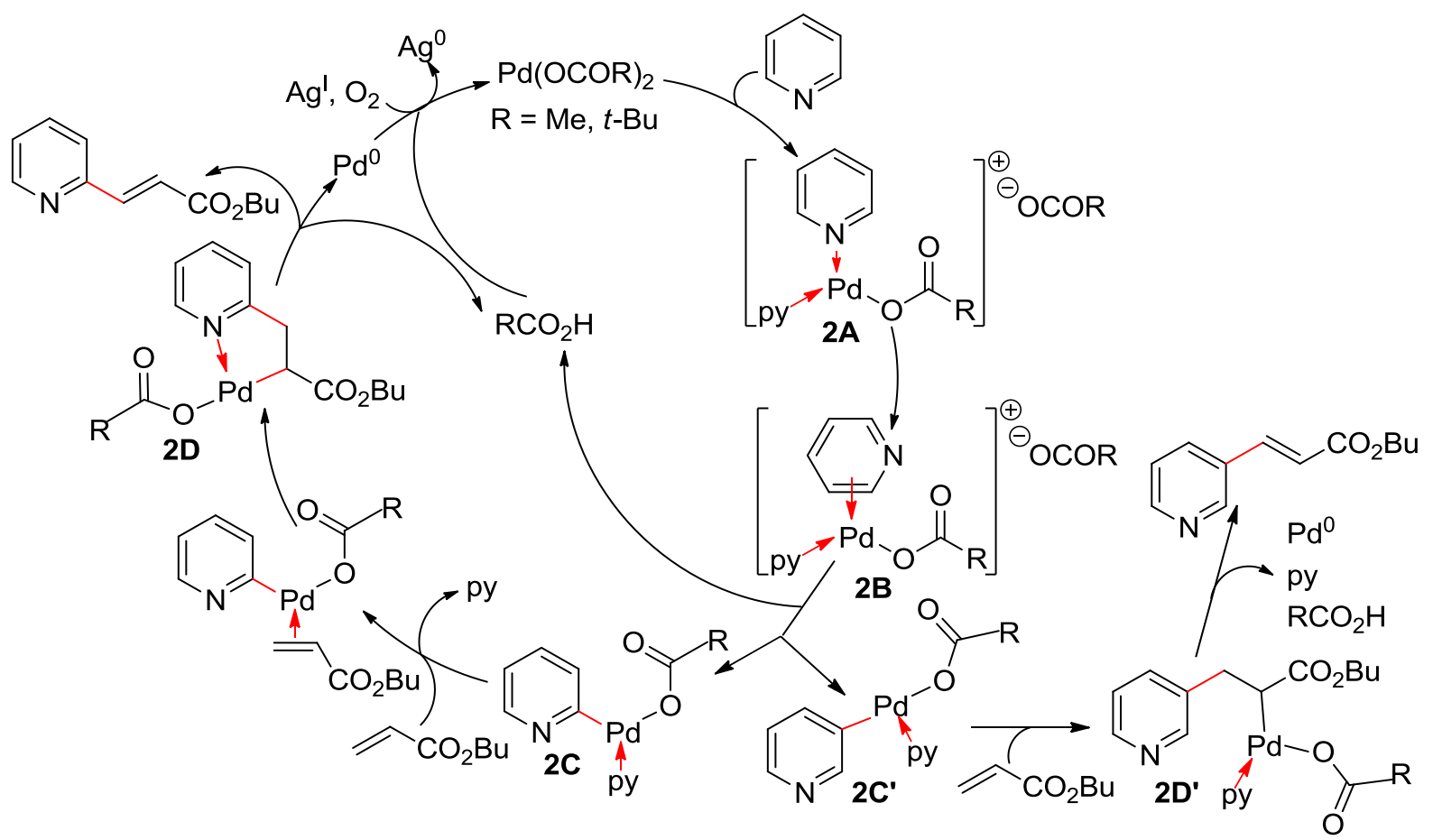

Scheme 2. Catalytic cycle adapted from [18].

Another protocol for $\mathrm{C} 3$ olefination of pyridines was reported 18 months later by the team of Wu and Zeng [23]. While only traces of the $\mathrm{C} 3$ cross-coupling product were produced from pyridine and butyl acrylate under oxygen and $\mathrm{Pd}(\mathrm{OAc})_{2}$ catalysis at $130{ }^{\circ} \mathrm{C}$ in 2-methylbutan-2-ol containing $\mathrm{KHCO}_{3}$, the DHR arose in fair yields in the presence of mono-N-protected amino acids, especially $\alpha$-isopropyl-substituted L- $N$-acetyl-valine (Ac-Val$\mathrm{OH}$ (Eq. 4). The procedure was used for the selective 3-alkenylation of various pyridines with acrylates, $N, N$ dimethylacrylamide and (hetero)styrenes (23 examples, $20-80 \%$ yield). The DHR also occurred with substituted acrylates (Eqs 5 and 6$)$. The $\mathrm{KIE}\left(k_{\mathrm{H}} / k_{\mathrm{D}}=3\right)$ lower than those obtained under the other experimental conditions [13] "is consistent with a thermodynamically unfavorable $\mathrm{C}-\mathrm{H}$ activation step, and it may indicate that the AcVal-OH ligand enhances the electrophilic property of the palladium center in promoting the $\mathrm{C}-\mathrm{H}$ bond cleavage of pyridine" [23]. In a few cases, the olefination was carried out in DMA under air with $\mathrm{Ag}_{2} \mathrm{CO}_{3}$ as additive (Eq. 7). Given a recent report from Sunoj's team [24], the silver salt could be more than a terminal oxidant, forming a $\mathrm{Pd} / \mathrm{Ag}$ heterobimetallic species which would participate in the catalytic cycle. 


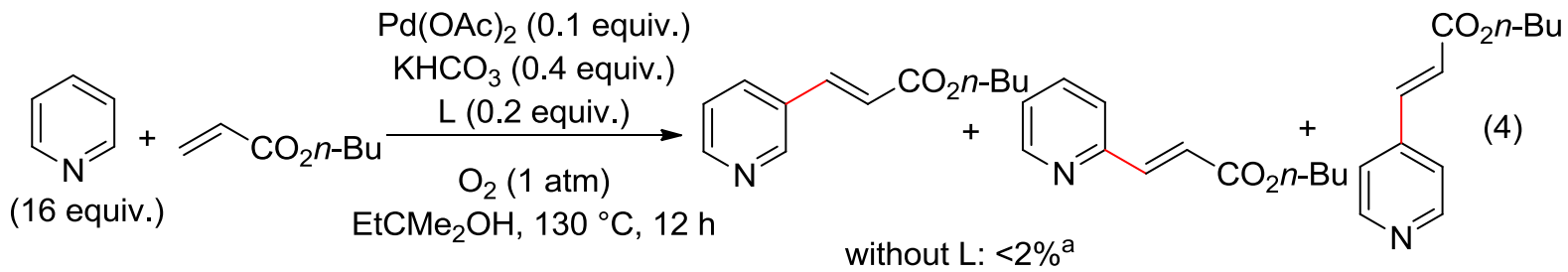

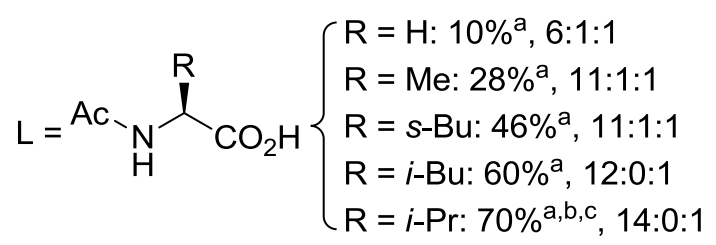

${ }^{a}$ Isolated yield of the $\mathrm{C}-3$ cross-coupling product

${ }^{\mathrm{b}} 42 \%$ under air instead of $\mathrm{O}_{2}$

${ }^{c} 40 \%$ with $\mathrm{PdCl}_{2}$ instead of $\mathrm{Pd}(\mathrm{OAc})_{2}$.<smiles>[R]OCC=C(C)c1cccnc1</smiles>
(16 equiv.)

$\mathrm{EtCMe}_{2} \mathrm{OH}, 130^{\circ} \mathrm{C}, 12 \mathrm{~h}$

$42 \%, 1: 2$

$\mathrm{Pd}(\mathrm{OAc})_{2}$ (0.1 equiv.)

$\mathrm{KHCO}_{3}$ (0.4 equiv.), $\mathrm{Ag}_{2} \mathrm{CO}_{3}$ ( 0.5 equiv.)

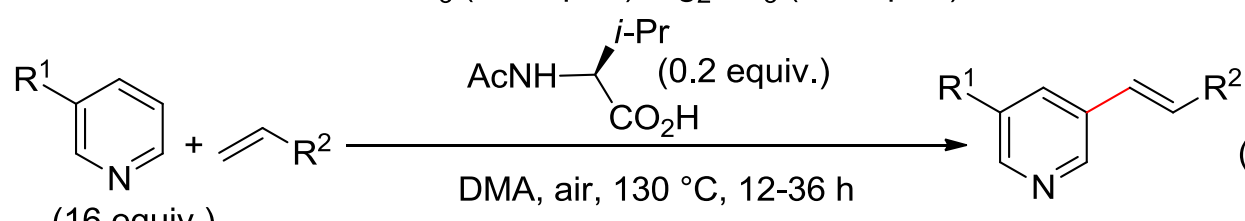

(16 equiv.)

$$
\mathrm{R}^{1}=\mathrm{H}, \mathrm{R}^{2}=\mathrm{Ph} ; 44 \% ; \mathrm{R}^{1}=\mathrm{CN}, \mathrm{R}^{2}=\mathrm{CO}_{2} \mathrm{n}-\mathrm{Bu} ; 35 \%
$$

$\mathrm{Wu}$, Zeng and co-workers assumed a crucial role to Ac-Val-OH becoming either one electron donor (Xtype) or a two electron donor (L-type) ligand [23]. The proposed intermediates (Scheme 3) agree with extensive theoretical studies by density functional theory. From intermediate $\mathbf{3 A}$, proton abstraction transforms the LXtype bidentate ligand into a XX-type ligand giving $3 \mathrm{~B}$ and $\mathrm{AcOH}$. Calculations indicated that the activation of $\mathrm{C} 3-\mathrm{H}$ is favored over $\mathrm{C} 4-\mathrm{H}$ and especially $\mathrm{C} 2-\mathrm{H}$. That results in transition state $\mathbf{3 C}$. Intramolecular proton abstraction by the acetoxy ligand [25] and protonation of the $\mathrm{N}$ atom by previously liberated $\mathrm{AcOH}$ affords $\mathbf{3 D}$. The LX-type bidentate ligand of 3D undergoes exchange with the alkenating agent leading to $\mathbf{3 E}$. Insertion of $\mathrm{C}=\mathrm{C}$ bond into the $\mathrm{Pd}$-pyridinyl bond gives $\mathbf{3 F}$. Subsequent $\beta$ - $\mathrm{H}$ elimination liberates the $\mathrm{C} 3$ adduct, $\mathrm{Ac}-\mathrm{Val}-\mathrm{OH}$ and, according to the authors, $\mathrm{Pd}^{0}$ and $\mathrm{AcOH}$. Reaction of $\mathrm{Pd}^{0}$ with $\mathrm{O}_{2}$ and $\mathrm{AcOH}$ would regenerate $\mathrm{Pd}(\mathrm{OAc})_{2}$. 
The regeneration of active $\mathrm{Pd}$ species could also arise from reaction of $\mathrm{PdH}$ intermediate with $\mathrm{O}_{2}$ [26] but such a pathway remains a matter of debate $[27,28]$. The role of the solvent is however ignored in this catalytic cycle. Indeed, 2-methylbutan-2-ol could cause the alcoholysis of palladium acetate leading to alkoxypalladium species as the active catalyst [29].

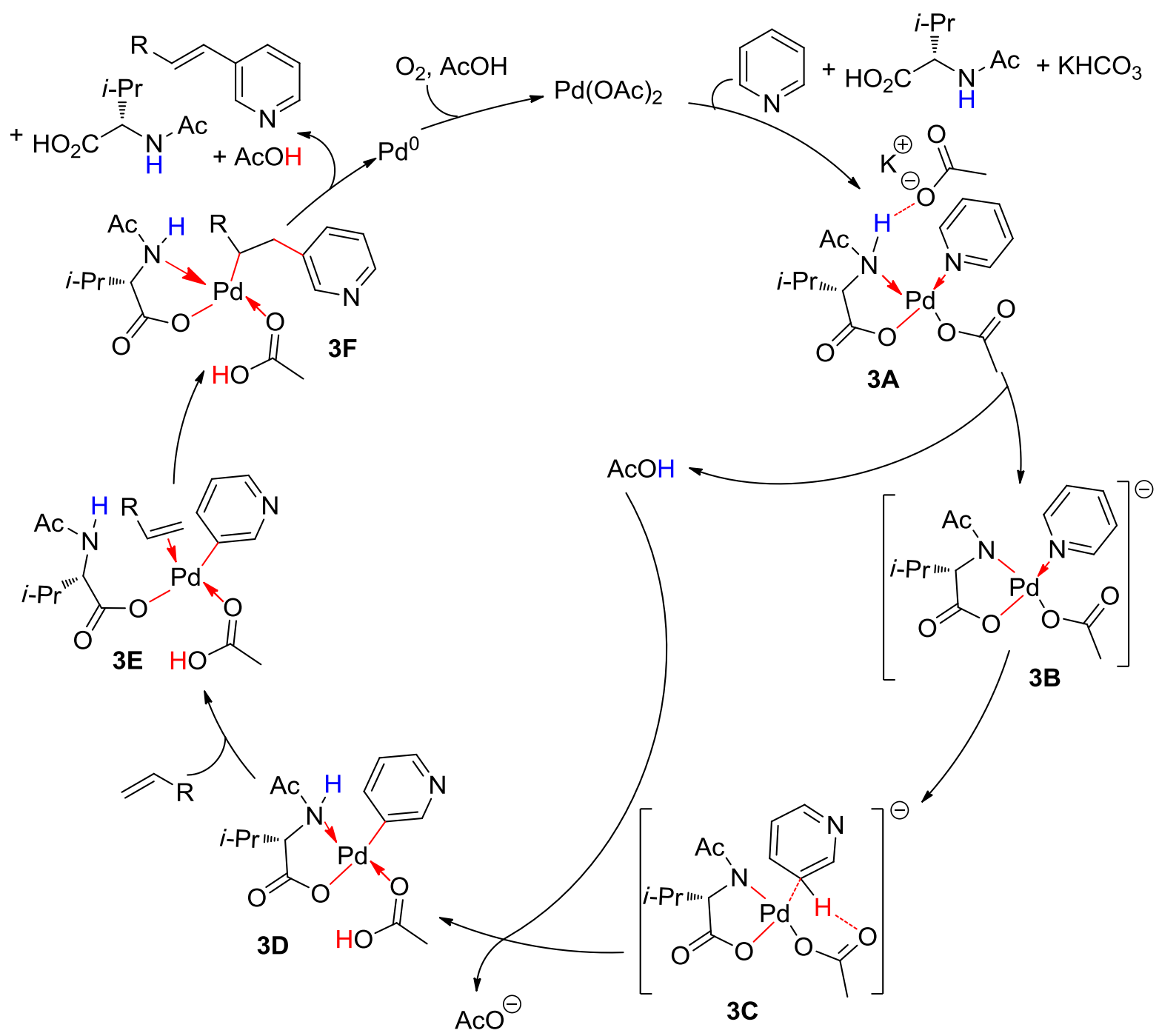

Scheme 3. Catalytic cycle adapted from [23].

Below, we tentatively rationalize the regioselectivity dependence of pyridine on the experimental conditions

Calculations favor the C3 olefination [23,30,31]. In 2013, Yu's team nevertheless noted that "the strong preference for $\mathrm{C}-\mathrm{H}$ cleavage at the $\mathrm{C} 3$ position is not entirely clear at this time" [22]. Computational analysis of the Pd-catalyzed arylation of pyridine [32] led Gorelsky to assume that the selectivity "is expected to switch from $\mathrm{C} 3$ arylation to $\mathrm{C} 2$ arylation" when pyridine is $\mathrm{N}$-coordinated to $\mathrm{Cu}^{\mathrm{I}}$ [31]. Thus, we suspected that the $\mathrm{C} 2$ selective olefination (Eq. 2) is due to a pyridine molecule $\mathrm{N}$ - and $\mathrm{C} 2$-coordinated to $\mathrm{Pd}$ atoms as the corresponding key intermediate.

Under the experimental conditions of $\mathrm{Yu}, \mathrm{Wu}, \mathrm{Zeng}$ and co-workers, the $\mathrm{C} 3$ selectivity occurred even in the absence of the bidentate ligand but the yield was lower (Eqs 1 and 4) [13,23]. Moreover, some relationship between selectivity and steric hindrance of the bidentate ligand was observed. Thus, the $\mathrm{C} 2$ position would be disfavored by steric effect [22]. The bidentate ligand increases the nucleophilicity of the $\mathrm{Pd}^{\mathrm{II}}$ center favoring the concerted metalation/deprotonation [33] of the heteroarene ring.

The main difference between the procedures of the teams of Yu, Ma and Huang (Eqs 1 and 2) [13,18] is pivalic acid (Eq. 2), this additive reversing the selectivity. The nature of the silver salt could also have an influence, but more experiments would be required to clarify this plausible effect. Both procedures (Eqs 1 and 2) 
use the same coordinating solvent, DMF [34,35], at $140^{\circ} \mathrm{C}$. 2-Methylbutan-2-ol which is the solvent of the Wu and Zeng method (Eq. 4) [23] probably has coordination properties probably lower than those of DMF [35]. Consequently, the $\mathrm{C} 3$ versus $\mathrm{C} 2$ selectivity is most likely not linked to the solvent.

The complexes $\mathrm{Pd}(\mathrm{OAc})_{2}(\mathrm{py})_{2} \mathrm{H}_{2} \mathrm{O}$ [36] and $\mathrm{Pd}(\mathrm{OAc})_{2}$ (2,6-bis(2-ethylhexyl)pyridine $)_{2}$ [37] have been characterized by $\mathrm{X}$-ray crystallography. In solution, the latter evolved towards $\left[\mathrm{Pd}(\mathrm{OAc})_{2}(2,6-\mathrm{bis}(2-\right.$ ethylhexyl)pyridine $)]_{2}$ in which the $\mathrm{Pd}(\mathrm{OAc})_{2}$ units are joined by double $\mathrm{OAc}$ bridges [37]. Palladium acetate exists as a trimer (4A) in the solid state (Scheme 4) [38]. The structure is maintained in $\mathrm{AcOH}$ [39], $\mathrm{EtCO}_{2} \mathrm{H}$ and $\mathrm{EtCO}_{2} \mathrm{H} / \mathrm{THF}$ mixture [40]. The close donating properties of THF and DMF [35] would lead to suspect that structure 4A could be more or less [41] maintained in DMF and also be the structure for the Pd catalyst of Scheme 2 [42]. The yield dependence of the $\mathrm{C} 2$ olefination of pyridine (Eq. 2) with both nature and amount of the used carboxylic acid $[18,43]$ as well as the superiority of the pivalate ligand over the acetate to abstract a proton $[44-46]^{2}$ led us to assume that the trimer could rather be $4 \mathrm{~B}(\mathrm{R}=t$-Bu). Given the above pyridine complexes and the above Gorelsky remark [31], we propose that under experimental conditions of Eq. 2, coordination of pyridine molecules to $\mathrm{Pd}$ atoms leads to some cleavage of bridging ligands, resulting in the formation of dimer $\mathbf{4 C}$ from $\mathbf{4 B}[33,46,47] .4 \mathrm{C}$ could also be obtained from the dimer $\left[\mathrm{Pd}(\mathrm{OCO} t-\mathrm{Bu})_{2}\right]_{2}$ which would have a good stability [48]. The coordinating properties of pyridine superior to those of DMF [35a] led us to draw 4C without ligation of DMF. H-abstraction by the pivalate ligand [49] affords 4D from 4C. Then, the reaction proceeds as depicted in Scheme 2. The $\mathrm{C} 2$ olefination being carried out in presence of a silver salt (Eq. 2 ), the DHR could be catalyzed by heterobimetallic species [24,50] resulting in an intermediate similar to $\mathbf{4 C}$ for which the $\mathrm{N}$ atom is coordinated to $\mathrm{Ag}$ instead of $\mathrm{Pd}$.

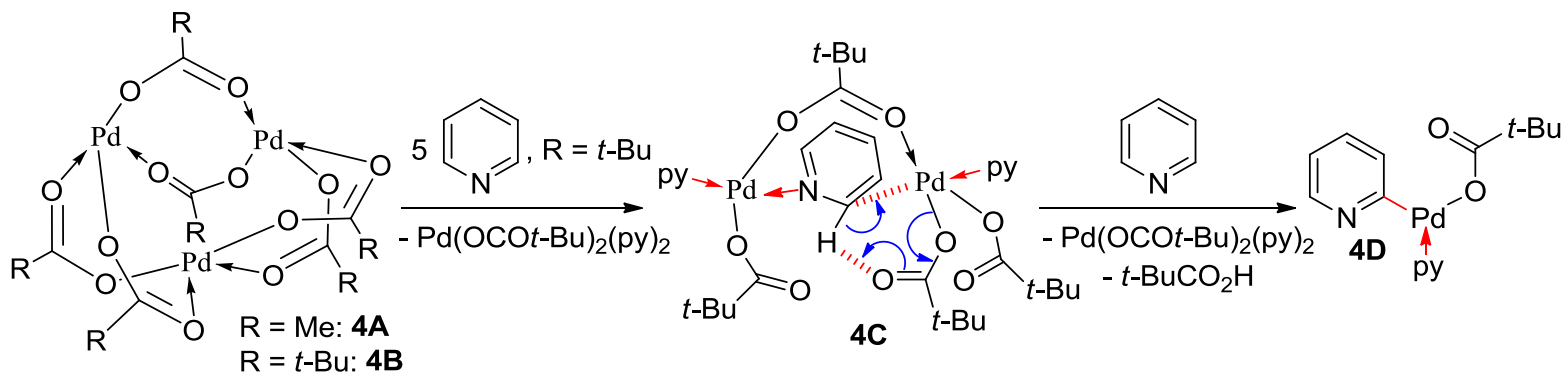

Scheme 4. A plausible transition state to rationalize the $\mathrm{C} 2-\mathrm{H}$ activation.

Su's team disclosed the Pd-catalyzed olefination of (hetero)arenes with saturated ketones, one example being the reaction of 2,3,5,6-tetrafluoropyridine with propiophenone which afforded (E)-3-(perfluoropyridin-4yl)-1-phenylprop-2-en-1-one (Eq. 8) [51] through a domino dehydrogenation/Heck-type reaction [52]. The authors showed that the reaction arose via Pd-catalyzed dehydrogenation of the ketone into 1-phenylprop-2-en-1one [53] followed by Pd-catalyzed DHR.<smiles>O=C([Pb])/C=C/c1c(F)c(O)nc(F)c1F</smiles>

\subsection{Pyridones}

In 2012, Li's team reported the efficient $\mathrm{Pd}(\mathrm{OAc})_{2}$-catalyzed $\mathrm{C} 5$ olefination of $\mathrm{N}$-substituted pyridin- $2(\mathrm{H})$ ones in pivalic acid at $110^{\circ} \mathrm{C}$ with $\mathrm{Cu}(\mathrm{OAc})_{2}$ as the oxidant (Eq. 9) [54]. Lower yields were obtained in $\mathrm{AcOH}$, toluene, DMF/DMSO and acetone. The DHR of 1,3-disubstituted pyridin-2(1H)-one arose with the same regioselectivity (Eq. 9) while $N$-methylpyridin-2(1H)-ones substituted in 4,5 or 6 position were olefinated in C3

\footnotetext{
${ }^{2}$ The superiority of pivalate could be related to both its larger steric bulk and its stronger basicity $[44,45 c]$.
} 
position (Eq.10). Olefination of both C3 and C5 positions of N-substituted pyridin-2(1H)-ones occurred via either sequential addition or one-pot in increasing the amount of acrylates. Use of allyl acetate instead of acrylates led to a DHR associated to a Tsuji-Trost reaction [55] giving $\mathrm{C}-\mathrm{H}$ substitution by the allyl pivalate group (Eq. 11).
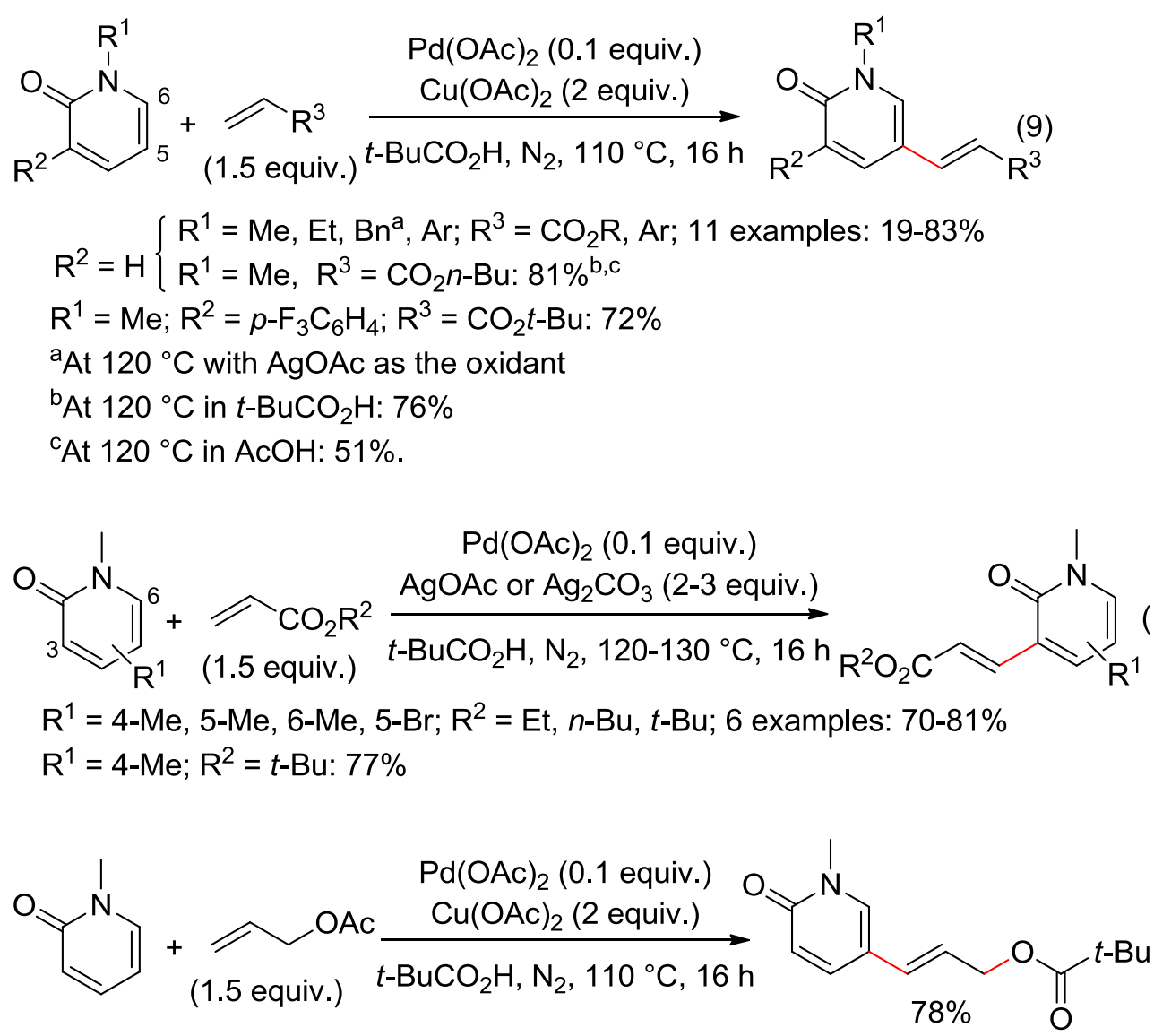

Heating 1-methylpyridin-2(1H)-one and 1,4-dimethylpyridin-2(1H)-one with catalytic $\mathrm{Pd}(\mathrm{OAc})_{2}$ in $\mathrm{CD}_{3} \mathrm{CO}_{2} \mathrm{D}$ resulted in main $\mathrm{H} / \mathrm{D}$ exchange in $\mathrm{C} 5$ position (Eq. 12) although the DHR of the disubstituted substrate selectively occurred in $\mathrm{C} 3$ position (Eq. 10). According to Li and co-workers, "this discrepancy can be reconciled by the inversion of relative rate of subsequent reactions when an olefin is present" and the site selectivity of the DHR "is subtly tuned by a combination of electronic and steric effects" [54].

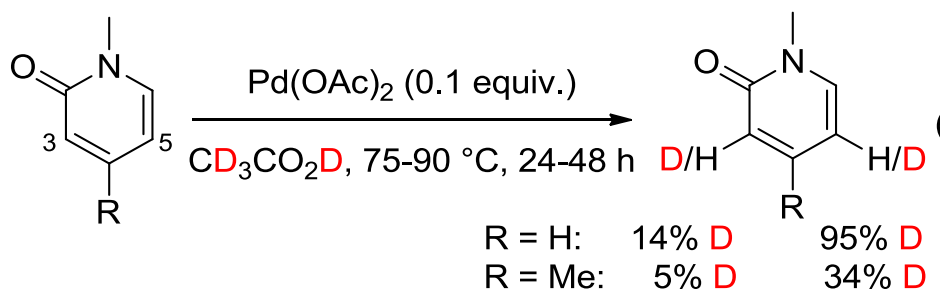

Bäckvall's team developed an aerobic oxidation system consisting of catalytic amounts of $\operatorname{Pd}(\mathrm{OAc})_{2}$, benzoquinone (BQ) and an electron-transfer mediator, especially iron phthalocyanine $(\mathrm{Fe}(\mathrm{Pc}))$ [56]. The procedure has been used for the $\mathrm{C} 5$ olefination of $N$-methylpyridin-2(1H)-one in pivalic acid at $120^{\circ} \mathrm{C}(\mathrm{Eq} .13)$ [57]. The yields dramatically decreased in a mixture of AcOH and DMA at $70{ }^{\circ} \mathrm{C}$. The mechanism proposed by Bäckvall and co-workers for the regeneration of active catalytic species is illustrated in Scheme 5. As depicted in Scheme 1, the DHR leads to $\mathrm{Pd}^{0}$ and $2 \mathrm{AcOH}$. Coordination of benzoquinone to $\mathrm{Pd}^{0}$ form a complex which undergoes reaction with $\mathrm{AcOH}$ giving $\mathrm{Pd}(\mathrm{OAc})_{2}$ and hydroquinone [58,59]. Oxidation of hydroquinone into 
benzoquinone cannot occur with molecular oxygen but arise in the presence of the electron-transfer mediator, hence a cross-coupling reaction mediated with only catalytic amounts of $\mathrm{Pd}(\mathrm{OAc})_{2}, \mathrm{BQ}$ and $\mathrm{Fe}(\mathrm{Pc})[56]$.

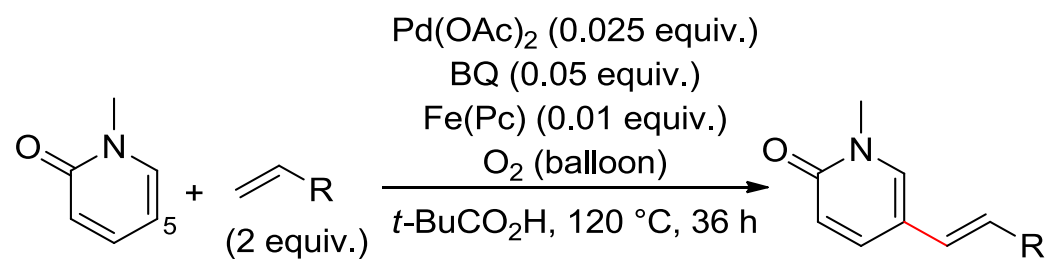

$\mathrm{R}=\mathrm{CO}_{2} \mathrm{Me}(53 \%)^{\mathrm{a}}, \mathrm{PO}(\mathrm{OEt})_{2}(62 \%), \mathrm{SO}_{2} \mathrm{Ph}(49 \%)$

${ }^{\mathrm{a}} 19 \%$ in $\mathrm{AcOH} / \mathrm{DMA}(1: 1)$ at $70{ }^{\circ} \mathrm{C}$ for $24 \mathrm{~h}$.

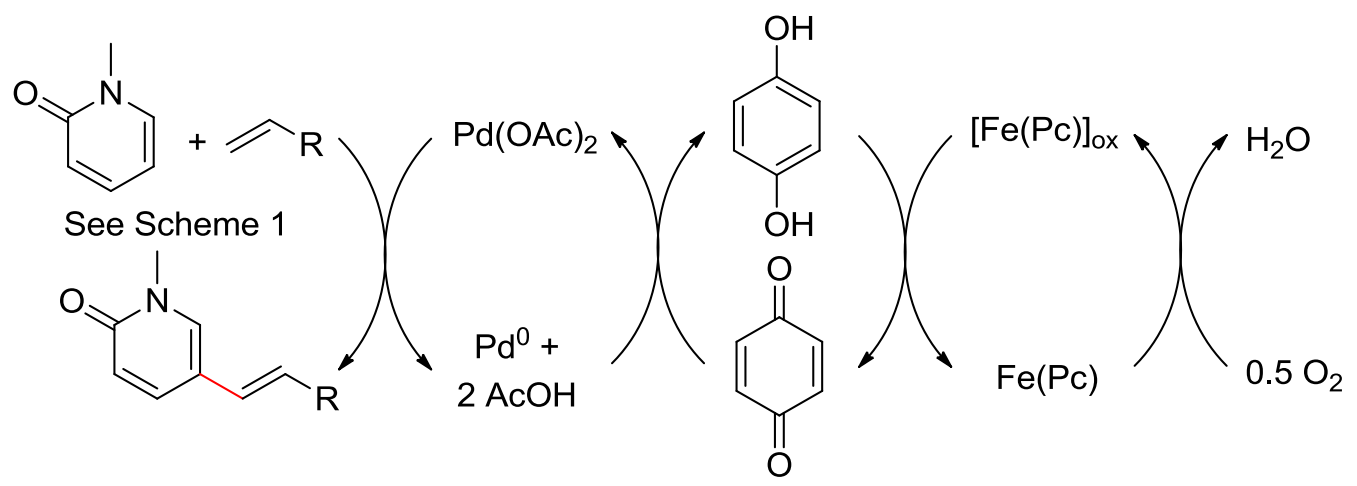

Scheme 5. Catalyst regeneration using an electron-transfer mediator.

Yousuf's team carried out the selective $\mathrm{C} 3$ alkenylation of 4-hydroxypyridin-2(1H)-one with styrenes using catalytic amounts of both $\mathrm{Pd}(\mathrm{OAc})_{2}$ and $\mathrm{Cu}(\mathrm{OTf})_{2}$ in aerated $\mathrm{DMF} / \mathrm{DMSO}$ at $80{ }^{\circ} \mathrm{C}$ (Eq. 14) [60].

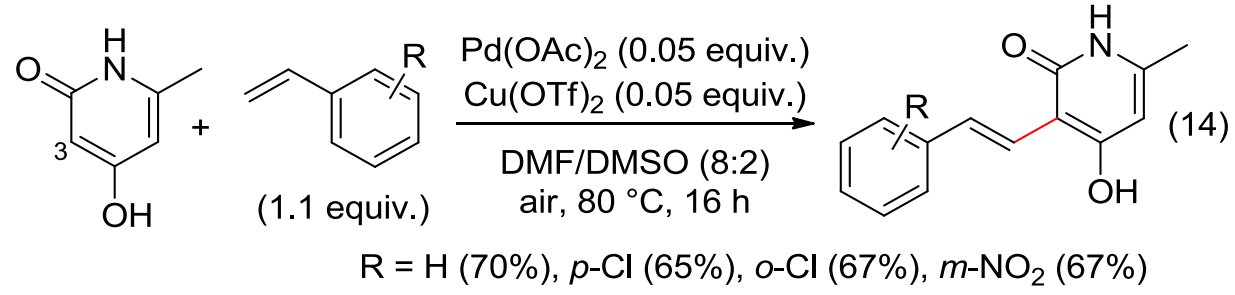

A domino reaction arose from 4-hydroxy-1-methylpyridin-2(1H)-one and 1-hexene leading to cyclisation products (Eq. 15) [61]. Homocoupling of the aromatic substrate may be a side-product. Various Pd-catalysts, oxidants and solvents, with or without base or carboxylic acid, afforded the products. The best yield and selectivity were obtained with $\mathrm{Pd}(\mathrm{OAc})_{2}$ as the catalyst, $\mathrm{Cu}(\mathrm{OAc})_{2}$ as the oxidant and formic acid as the additive in $\mathrm{MeCN}$. The reaction with styrene, which efficiently led to the cyclized product (Eq. 16) contrasts with that under Yousuf's conditions (Eq. 14). With shorted alkenes such as 2-pentene, the reaction stopped at the level of the alkenylation (Eq. 17). The cross-coupling cyclisation with diethyl 2-methylenemalonate led to the formation of a pyranonyl ring (Eq. 18). 


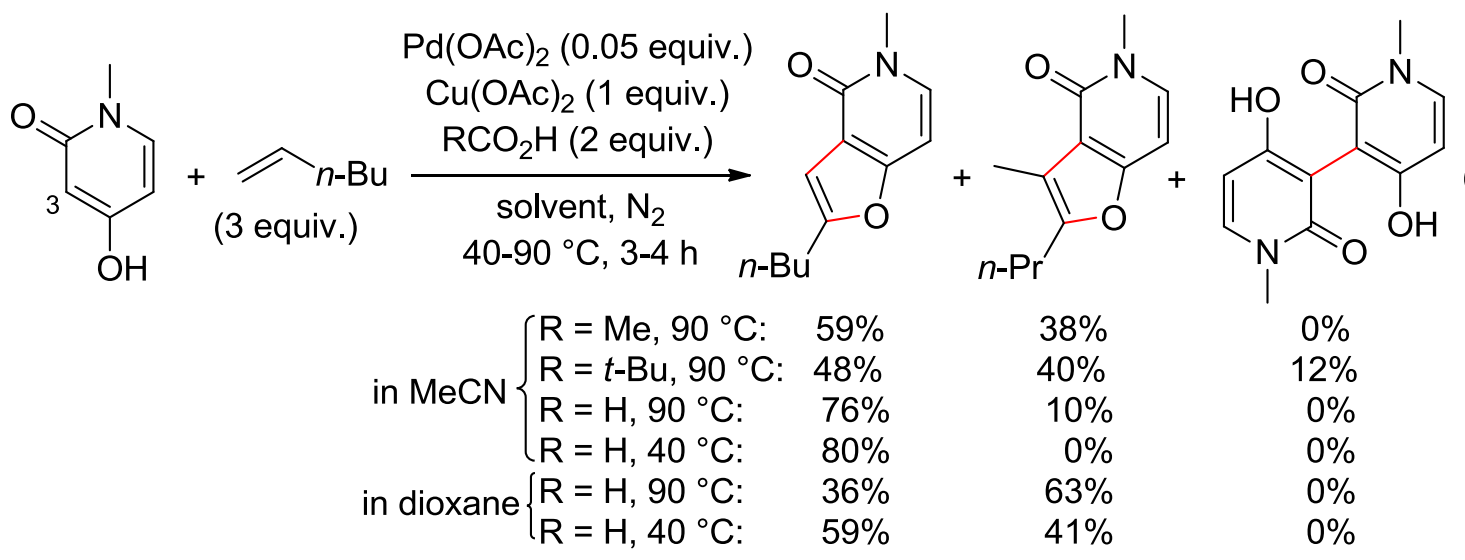<smiles>[R]OC(=O)C(=C)C(=O)OCC</smiles>

(16)

The catalytic cycle depicted in Scheme 6, which is inspired by the proposal of Zografos and co-workers [61], involves $\mathrm{C} 3$ palladation of the substrate giving 6A. Coordination of 1-hexene followed by insertion into the C-Pd bond of $6 \mathrm{~B}$ gives $6 \mathrm{C}$ and/or $6 \mathrm{D}$. Coordination of the hydroxy group to palladium atom was already assumed by Yousuf's team for the intermediate leading to cross-coupling with styrenes (Eq. 14). Intramolecular reaction of $6 \mathrm{C}$ leads to palladacycle $6 \mathrm{E}$, which undergoes reductive elimination of $\mathrm{Pd}^{0}$ giving $6 \mathrm{~F}$. Zografos team assumed that the main isolated product arises from in-situ oxidation of $\mathbf{6 F}$. The formation of the minor product is much less obvious. The authors showed the absence of isomerization of 1-hexene under the reaction conditions but were discreet on the reaction pathway. We propose a $\beta-\mathrm{H}$ elimination from $6 \mathrm{D}$ leading to $6 \mathrm{G}$ followed by successive addition/elimination of HPdOAc to provide $6 \mathbf{H}$. Subsequent intramolecular reaction gives $6 \mathbf{I}$ which evolves as assumed for $\mathbf{6 E}$. 


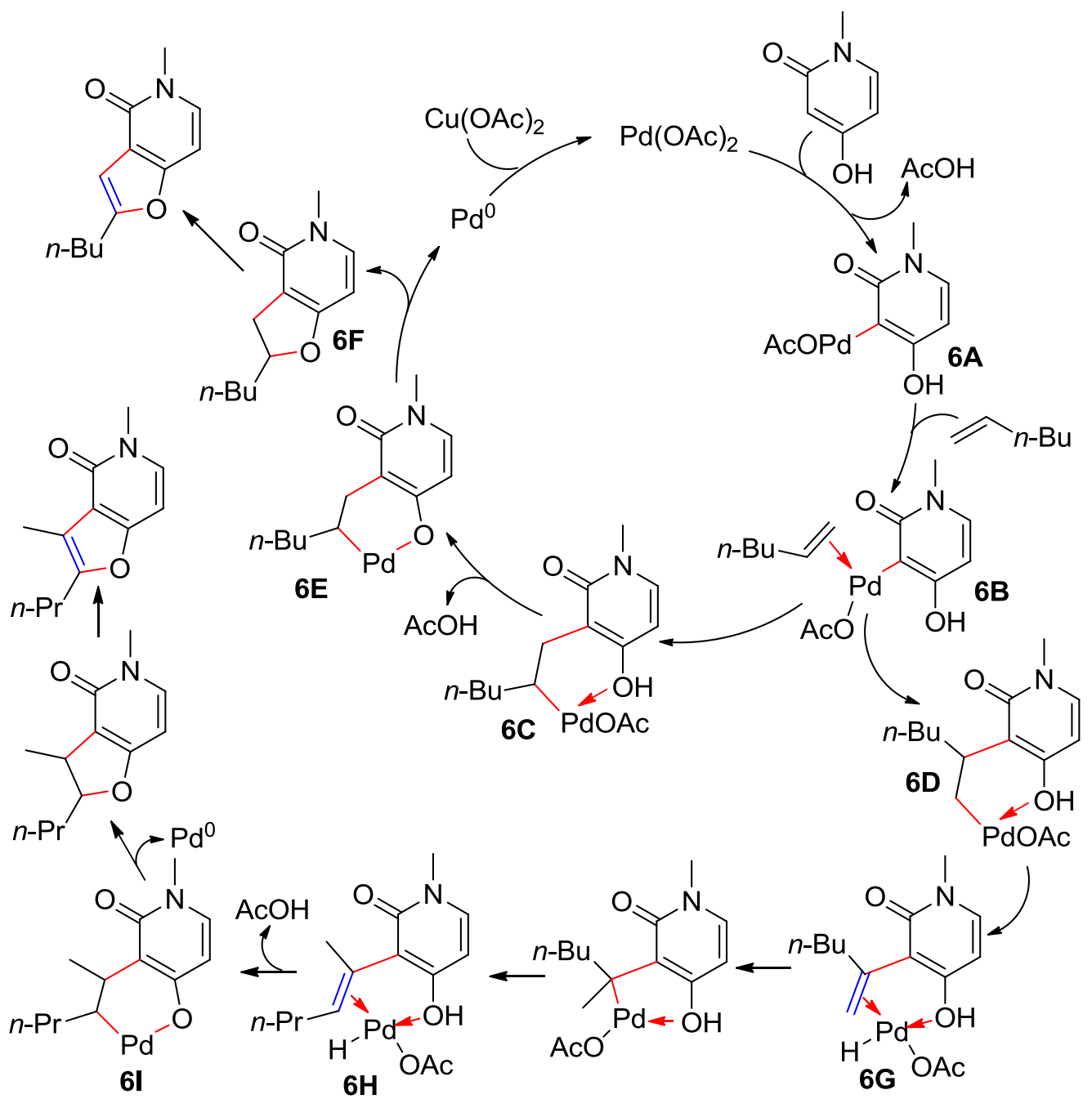

Scheme 6. Proposed intermediates of the cross-coupling/cyclisation reaction of 4-hydroxy-1-methylpyridin2(1H)-one.

The large dependence of the reaction selectivity of 4-hydroxy-1-methylpyridin-2(1H)-one on the nature of both the solvent and the carboxylic acid (Eq. 15) remains undetermined. On the basis of possible change of the insertion regioselectivity of alkenes into the C-Pd bond with the nature, cationic versus neutral, of Pd intermediates [62,63], the authors proposed "neutral-type mechanism in acetonitrile which changes to cationic when reaction is conducted in dioxane" [61]. We are rather sceptic towards this hypothesis because acetonitrile and dioxane have similar coordinating properties [35]. Both solvents can be involved as co-ligand in most intermediates shown in Scheme 6, especially 6B. Wucher and co-workers reported the influence of steric interactions on the regioselectivity of the addition of ArPd species to $\mathrm{CH}_{2}=\mathrm{CHR}$ [64]. Consequently, we suspect that the moderate size of $\mathrm{MeCN}$ favors the formation of $6 \mathbf{C}$ from $\mathbf{6 B}$, while the larger size of dioxane directs the insertion towards $6 \mathrm{D}$. Scheme 6 is drawn in considering a catalysis mediated by $\mathrm{Pd}(\mathrm{OAc})_{2}$, as proposed in the original report [61]. In fact, exchange with the carboxylic acid $\left(\mathrm{RCO}_{2} \mathrm{H}\right)$ used as additive could arise leading to PdOCOR-type intermediates with different steric hindrances, hence a plausible role of the size of $\mathrm{RCO}_{2} \mathrm{H}$ on the selectivity.

An array of 2,5-disubstituted pyridin-4(1H)-ones underwent $C 3$ alkenylation (Eq. 19) [65] under experimental conditions close to those of Ma and Huang (Eq. 2) [18]. Yao et al. showed that pivalic acid as additive was required for an effective DHR [65]. 

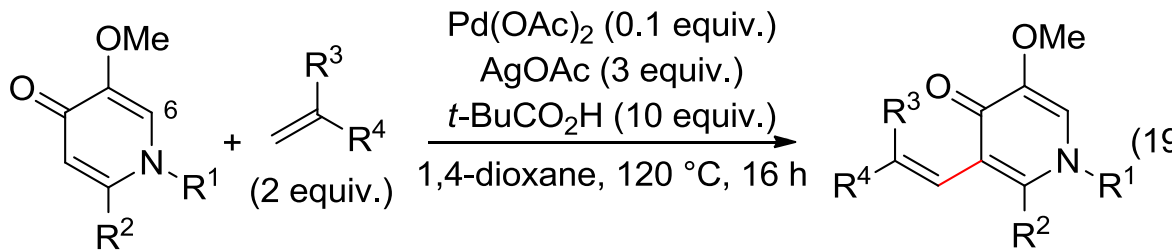

$\mathrm{R}^{1}=\mathrm{Me} ; \mathrm{R}^{2}=\mathrm{CH}_{2} \mathrm{OMe}\left\{\begin{array}{l}\mathrm{R}^{3}=\mathrm{H} ; \mathrm{R}^{4}=\mathrm{CO}_{2} \mathrm{R}, \mathrm{CONR}, \mathrm{CN}, \mathrm{Ph} ; 8 \text { examples: } 41-85 \% \\ \mathrm{R}^{3}=\mathrm{H} ; \mathrm{R}^{4}=\mathrm{CO}_{2} n-\mathrm{Bu}: 85 \%{ }^{\mathrm{a}, \mathrm{b}} \\ \mathrm{R}^{3}-\mathrm{R}^{4}=\left(\mathrm{CH}_{2}\right)_{2} \mathrm{CO}_{2} ; 71 \%\end{array}\right.$

$\mathrm{R}^{1}=\mathrm{Me} ; \mathrm{R}^{2}=\mathrm{CH}_{2} \mathrm{OTBS}, \mathrm{CH}_{2} \mathrm{OBn} ; \mathrm{R}^{3}=\mathrm{H} ; \mathrm{R}^{4}=\mathrm{CO}_{2} t-\mathrm{Bu} ; 2$ examples: $70-71 \%$

$\mathrm{R}^{1}=\mathrm{Et}, n-\mathrm{Pr}, i-\mathrm{Pr}, n-\mathrm{Bu}, \mathrm{Bn} ; \mathrm{R}^{2}=\mathrm{CH}_{2} \mathrm{OMe} ; \mathrm{R}^{3}=\mathrm{H} ; \mathrm{R}^{4}=\mathrm{CO}_{2} \mathrm{R} ; 8$ examples: $20-85 \%$

$\mathrm{R}^{1}=\mathrm{R}^{2}=\mathrm{Me}, \mathrm{R}^{3}=\mathrm{H}, \mathrm{R}^{4}=\mathrm{CO}_{2} t-\mathrm{Bu}: 61 \%$

aWith AgOAc (2 equiv.): $79 \%$

${ }^{\mathrm{b}}$ In absence of $t-\mathrm{BuCO}_{2} \mathrm{H}$ with $\mathrm{AgOAc}$ (2 equiv.): $54 \%$.

\subsection{Quinoline and isoquinoline}

The DHRs of quinoline and isoquinoline with acrylates, carried out using the above pyridine protocols, exhibited a regioselectivity highly depending on the procedure (Eqs 20-23) [13,18,23].

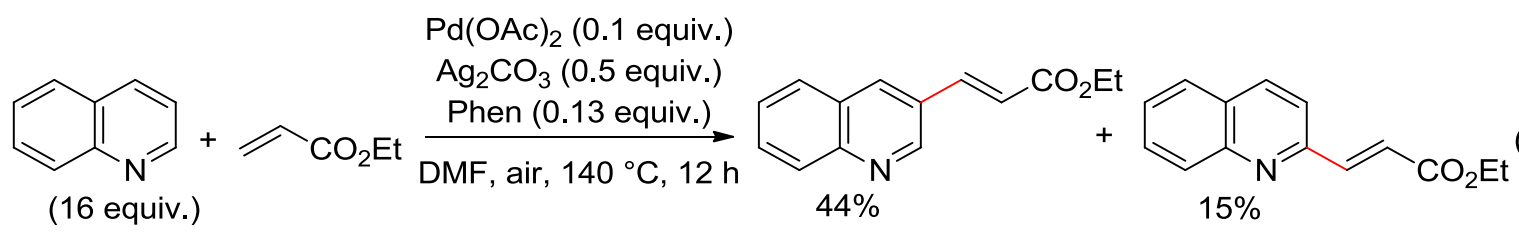

$\mathrm{Pd}(\mathrm{OAc})_{2}(0.1$ equiv. $)$

$$
\mathrm{AgOAc}(3 \text { equiv.) }
$$

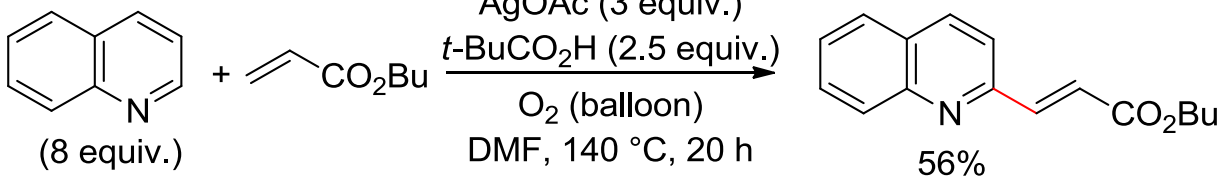

(8 equiv.)

DMF, $140{ }^{\circ} \mathrm{C}, 20 \mathrm{~h}$

$56 \%$

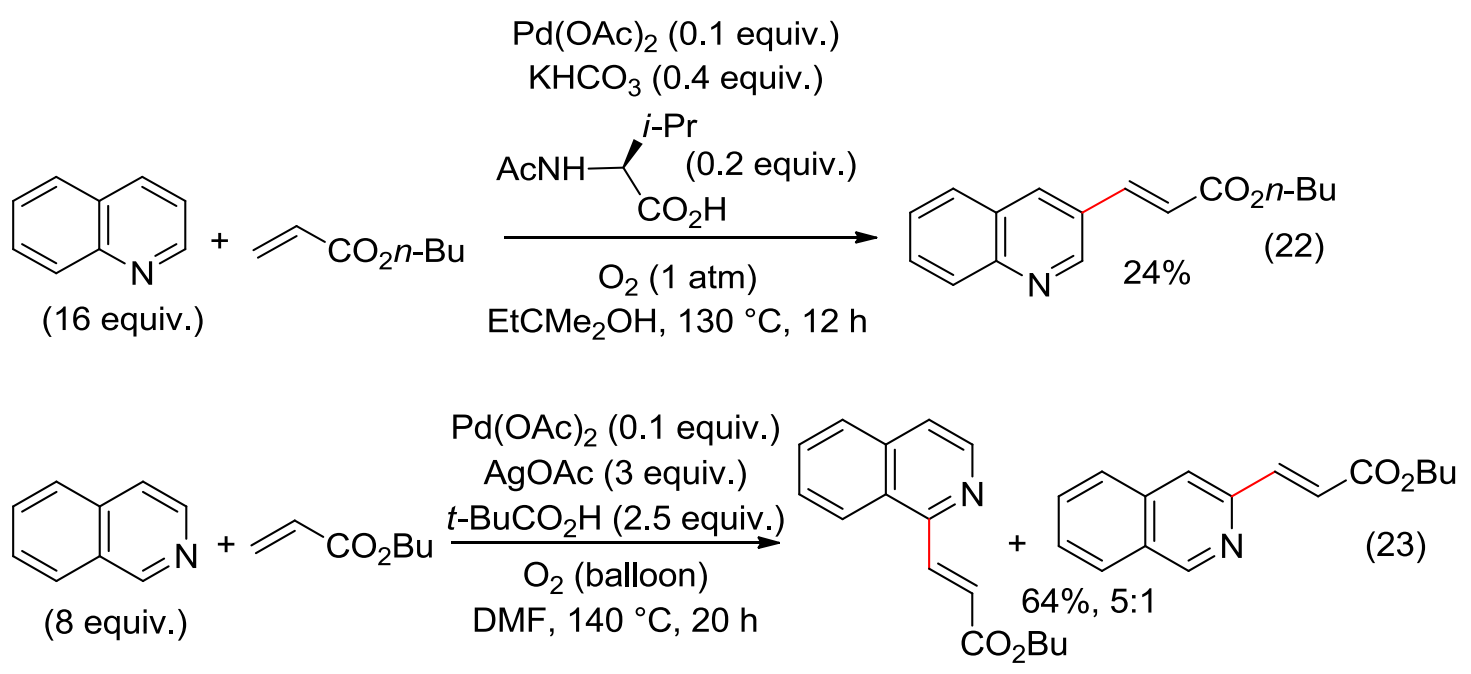

\subsection{Quinolones and 1,8-naphthyridin-4(1H)-one.}

An array of N-substituted quinolin-4(1H)-ones has been $\mathrm{C} 3$ alkenylated by Ge's team, using catalytic amounts of both $\mathrm{PdCl}_{2}$ (0.01 equiv.) and $\mathrm{Cu}(\mathrm{OAc})_{2}(0.1$ equiv.) in dioxane/DMSO under oxygen atmosphere (Eq. 24) [66]. N-substitution was required and the DHR efficiency depended on the nature of the substituents. 
The experimental conditions of the procedure ask the question of the mechanism and, consequently, on the nature of the catalytic species. The activation of the heteroaryl $\mathrm{C}-\mathrm{H}$ bond involves oxidative addition, $\sigma$-bond metathesis or electrophilic substitution $[46,67]^{3}$. Electrophilic substitution has been proposed for the $\mathrm{PdCl}_{2-}$ catalyzed DHR of isoquinoline and quinoline $N$-oxides (see below Eqs 29 and 30) [69]. Ge and co-workers however obtained the DHR of 1-methylquinolin-4(1H)-one with $t$-butyl acrylate in fair to high yields using $\mathrm{Pd}(\mathrm{OAc})_{2}$ (0.1-0.2 equiv.) or $\mathrm{Pd}\left(\mathrm{OCOCF}_{3}\right)_{2}\left(0.05-0.1\right.$ equiv.) with large amounts of $\mathrm{Cu}(\mathrm{OAc})_{2}$ (2 equiv.) under air atmosphere [66]. That leads us to suspect the in-situ formation of $\mathrm{XPdOAc}(\mathrm{X}=\mathrm{Cl}$ or $\mathrm{OAc})$ from $\mathrm{PdCl}_{2}$ and $\mathrm{Cu}(\mathrm{OAc})_{2}$; such a species could mediate the formation of the C-Pd bond via a concerted metalationdeprotonation pathway $[33,47]$.

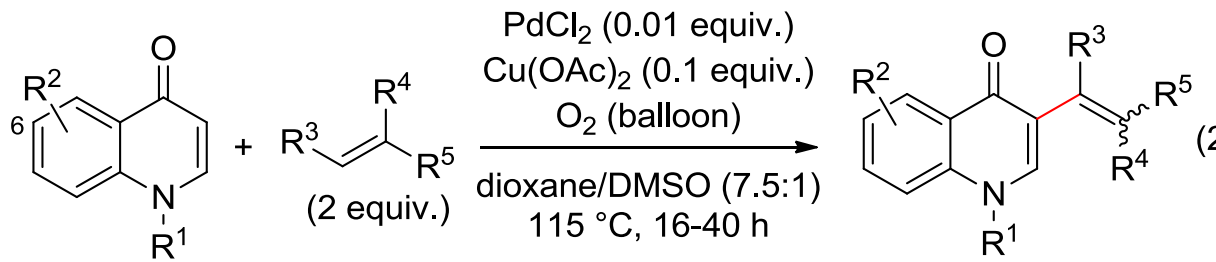

$$
\begin{aligned}
& R^{1}=M e\left\{\begin{array}{c}
R^{3}=R^{4}=\mathrm{H} ; R^{5}=C_{2} R, C_{2 N M e}, C O_{2} \mathrm{H}, \mathrm{Ar}, \mathrm{PO}(\mathrm{OEt})_{2}, \\
\mathrm{SO}_{2} \mathrm{Me} ; 11 \text { examples: } 49-94 \%
\end{array}\right. \\
& R^{2}=H\left\{R^{4}=H, R^{5}=C_{2} R, R^{3}=\mathrm{Me}(63 \%), \mathrm{CO}_{2} \mathrm{Et}(43 \%)\right. \\
& \mathrm{R}^{3}=\mathrm{H}, \mathrm{R}^{4}=\mathrm{Me}, \mathrm{R}^{5}=\mathrm{CN}(65 \%), \mathrm{CO}_{2} t-\mathrm{Bu}(66 \%) \\
& \mathrm{R}^{3}=\mathrm{R}^{4}=\mathrm{CO} \mathrm{CO}_{2} t-\mathrm{Bu}\left\{\begin{array}{c}
\mathrm{R}^{1}=\mathrm{R}^{2}=\mathrm{H}: 0 \% \\
\mathrm{R}^{1}=\mathrm{Bn}, \mathrm{R}^{2}=\mathrm{H}: 85 \% \\
\mathrm{R}^{1}=\mathrm{Me}, \mathrm{R}^{2}=6-\mathrm{Me}(97 \%), 6-\mathrm{Cl}(89 \%), 6-\mathrm{Br}(72 \%), \\
6-\mathrm{F}(89 \%), 6-\mathrm{CF}_{3}(88 \%), 6-\mathrm{OMe}(93 \%), 6-\mathrm{NO}_{2}(56 \%), \\
6-\mathrm{CO}_{2} \mathrm{Me}(67 \%), 6-\mathrm{COMe}(15 \%), 8-\mathrm{Me}(95 \%), \\
8-\mathrm{Me}(84 \%), 8-\mathrm{Br}(69 \%), 8-\mathrm{NO}_{2}(28 \%)
\end{array}\right.
\end{aligned}
$$

$\mathrm{N}$-substituted 2,3-dihydroquinolin-4(1H)-ones and 1-ethyl-7-methyl-2,3-dihydro-1,8-naphthyridin-4(1H)one underwent a domino dehydrogenation/dehydrogenative Heck reaction [52] catalyzed by $\mathrm{Pd}\left(\mathrm{OCOCF}_{3}\right)_{2}[26 \mathrm{a}]$ leading to cross-coupling products in high yields providing that pivalic acid was the solvent (Eq. 25) [70]. It seems of interest to note the absence of DHR at the level of the pyridinyl ring of the 1,8-naphthyridin- $4(1 \mathrm{H})$-one intermediate.

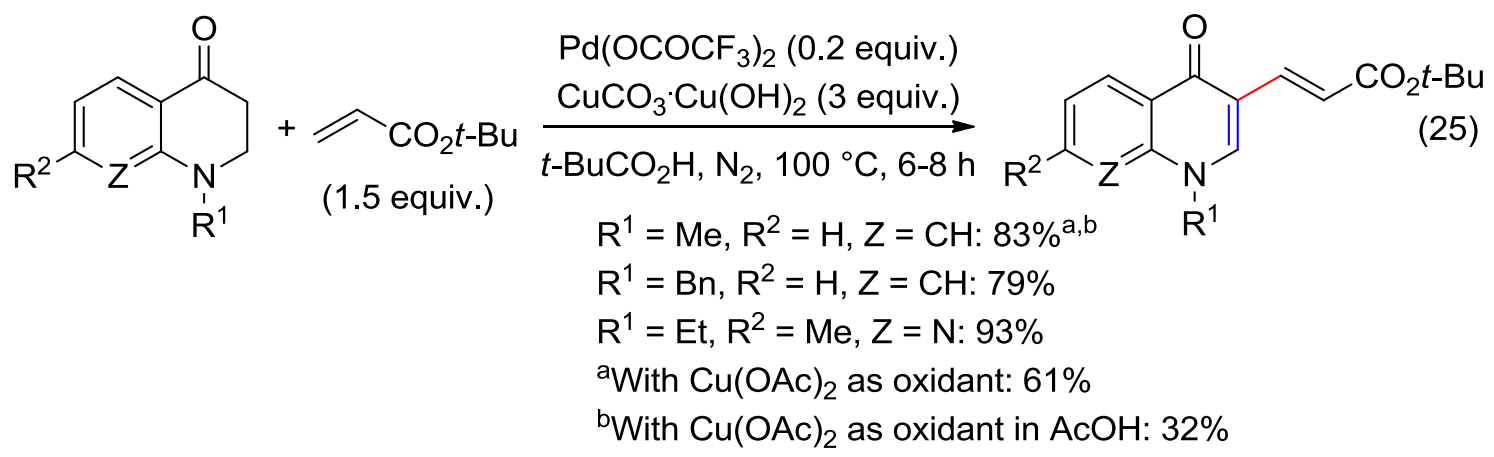

Three methods have been reported for selective $\mathrm{C} 3$ olefination of 1-methylquinolin-2(1H)-ones, all use pivalic acid either as solvent (Eqs 26 and 27) [54,71] or additive (Eq. 28) [72] and palladium acetate or pivalate as the catalyst.

\footnotetext{
${ }^{3}$ Computational studies to differentiate proton abstraction and electrophilic aromatic substitution mechanisms have been recently reported; the results were tested against literature experimental data [68].
} 


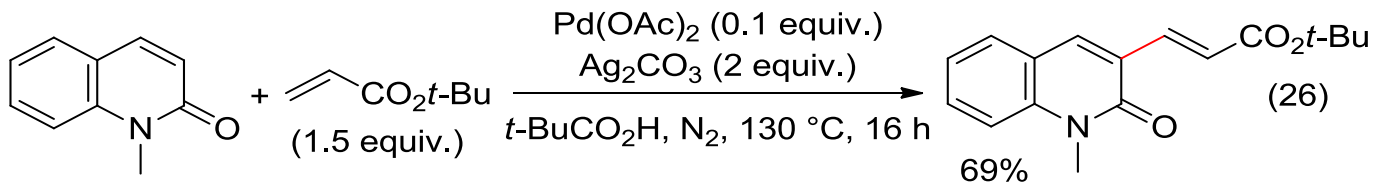

$\mathrm{Pd}(\mathrm{OCOt}-\mathrm{Bu})_{2}(0.2$ equiv. $)$<smiles>[R]C=Cc1cc2ccc(OC)cc2n(C)c1=O</smiles><smiles>[R]C=C([R10])C([R])=O</smiles><smiles>[R]/C(=C(\[R])C([R])C)c1c([R1])c2c(OC)cc(OC)cc2n(C)c1=O</smiles>

$\mathrm{R}^{1}=\mathrm{H}, \mathrm{Me}, \mathrm{Et}, \mathrm{Pr}, \mathrm{Ar} ; \mathrm{R}^{2}=\mathrm{O} t-\mathrm{Bu}, \mathrm{OMe}, \mathrm{NMe}_{2} ; \mathrm{R}^{3}, \mathrm{R}^{4}=\mathrm{H}, \mathrm{Me} ; 12$ examples: $49-84 \%$

\subsection{Pyridine $N$-oxides}

To the best of our knowledge, no Pd-catalyzed DHR of pyridine $N$-oxides was published since 2010 $[73]^{4}$. The mechanism of the $\mathrm{Pd}(\mathrm{OAc})_{2}$-mediated C-H activation of pyridine $\mathrm{N}$-oxide has however been investigated by Fang and Zhang through density functional theory (DFT) calculations [75]. While coordination of the catalyst to the $\mathrm{N}$-oxide was previously proposed as the step directing the regioselectivity of the C-Pd bond formation [76], DFT calculations indicated that the undirected mechanism is more plausible than the 4-memberdirected one both thermodynamically and kinetically [75]. Consequently, the C-H activation would involve transition state $\mathbf{7 A}$ rather than $\mathbf{7 B}$ (Scheme 7).

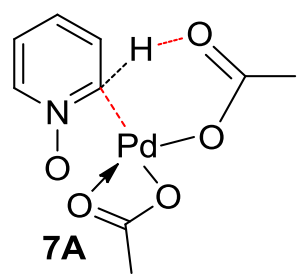<smiles></smiles>

Scheme 7. Plausible transition states of the C-H activation of pyridine $N$-oxide. Adapted from [75].

\subsection{Isoquinoline and quinoline $N$-oxides}

Liu's team carried out the olefination of isoquinoline and quinoline $\mathrm{N}$-oxides using catalytic $\mathrm{PdCl}_{2}$ in DMSO [69,77]. These substrates being prototypical oxygen atom transfer reagents [78], the reactions arose under external-oxidant-free conditions leading to 1-substituted isoquinolines (Eq. 29) and 2-substituted quinolines (Eq. 30), respectively. The reaction efficiency was highly dependent on the nature of both Pd catalyst and solvent (Eq. 29).

${ }^{4}$ The Pd-catalyzed C2 alkenylation of pyridine $N$-oxide with allyl acetate involves a Tsuji-Trost type reaction [74]. 


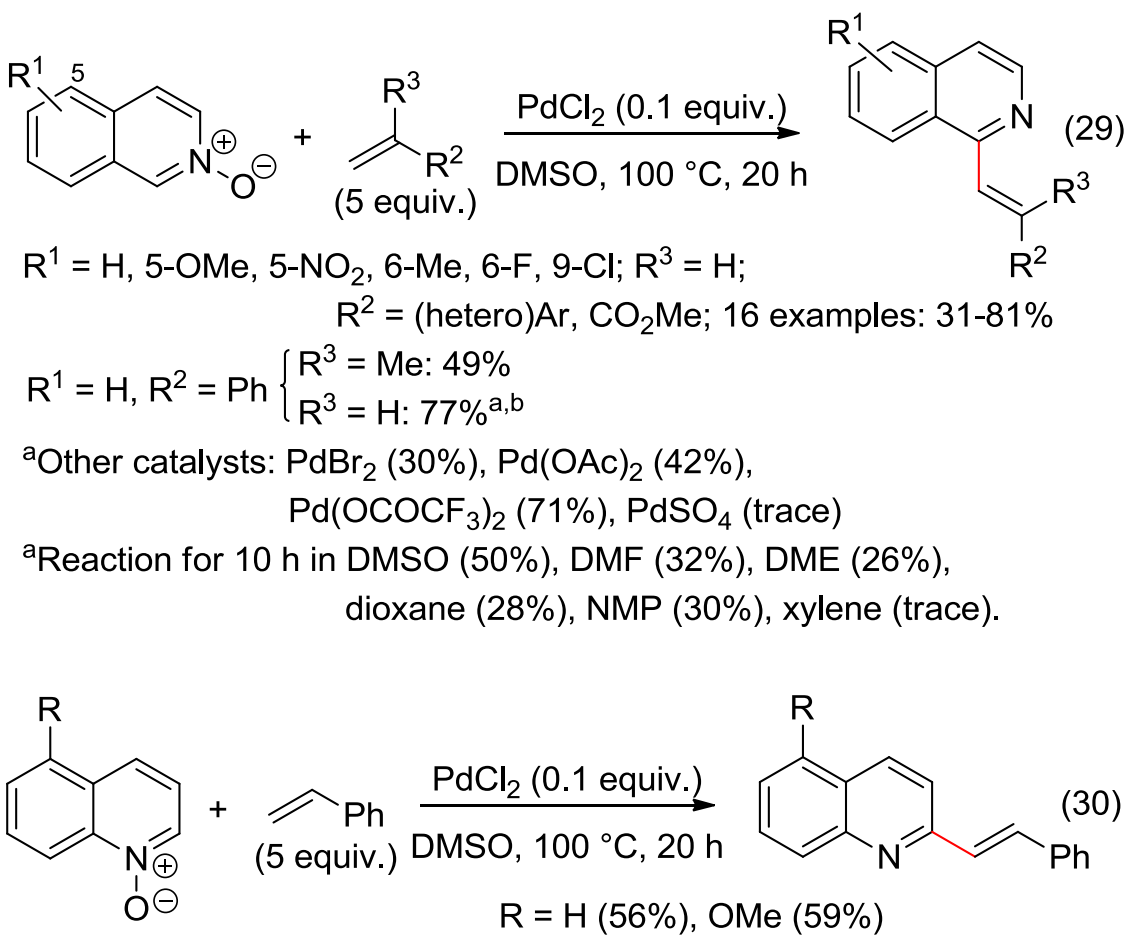

Liu's team proposed the formation of $\mathbf{7 A}$ from electrophilic attack of $\mathrm{PdCl}^{\oplus}$ to the isoquinoline $N$-oxide followed by rearomatization (Scheme 8) [69]. Coordination of the olefin to the Pd atom followed by insertion and $\beta$-H elimination leads to $\mathbf{8 B}$. Subsequent intramolecular reaction delivers the product and regenerates the catalyst. Note that the teams of Cui and $\mathrm{Wu}$ previously disclosed the transformation of quinoline $\mathrm{N}$-oxides under $\mathrm{Pd}(\mathrm{OAc})_{2}$ catalysis and external-oxidant-free conditions in 1-methyl-2-pyrrolidinone; they however proposed a catalytic cycle with coordination of $\mathrm{PdOAc}{ }^{\oplus}$ to the $N$-oxide before the electrophilic attack at the 2 position [76]. Recently, Chen and co-workers carried out DFT studies of the $\mathrm{C}-\mathrm{H}$ activation of quinoline $\mathrm{N}$-oxide [79], which agree with calculations of Fang and Zhang (see Sub-chapter 2.5) [75], and led to retain the undirected pathway, that is an intermediate corresponding to $\mathbf{8 A}$. Their calculations also match with the experimental preference for C2-H activation over $\mathrm{C} 8-\mathrm{H}$ activation of quinoline $N$-oxide ${ }^{\underline{5}}$.

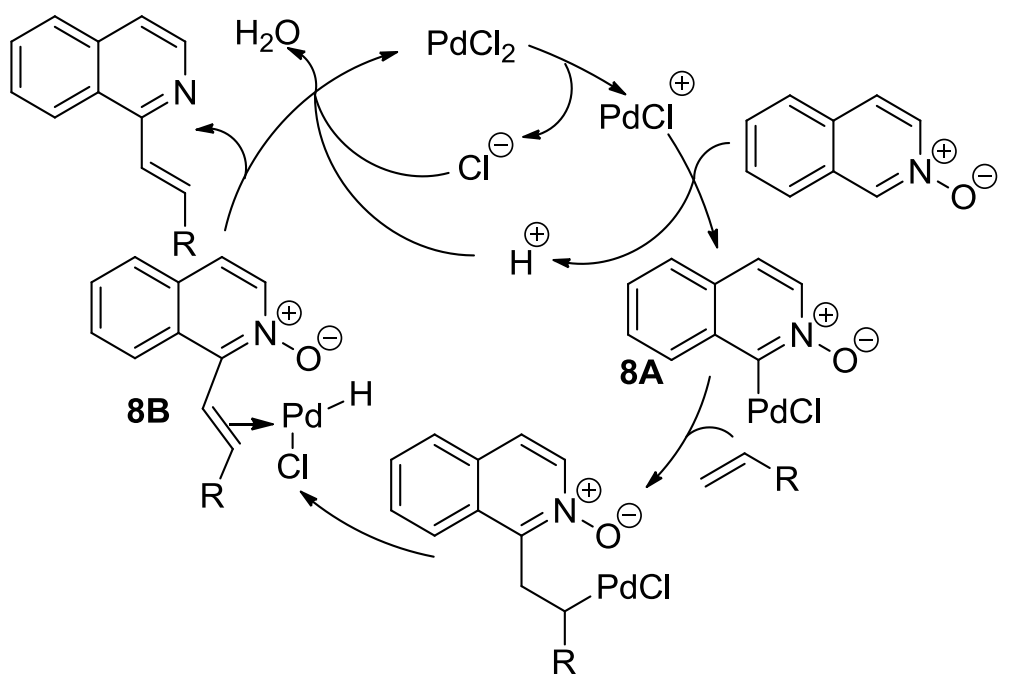

Scheme 8. Isoquinoline $N$-oxide as both substrate and oxidant.

\footnotetext{
${ }^{5}$ According to DFT calculations, the reported regioselective Pd-catalyzed C8 arylation of quinoline $\mathrm{N}$-oxide would arise via a cyclopalladation pathway [80].
} 
Recently, Vaccaro and co-workers proposed the use of a heterogeneous catalyst named "Polytag-Pd" obtained from $\mathrm{Na}_{2} \mathrm{PdCl}_{4}$ and an $\mathrm{N}$-containing ligand immobilized onto a polystyrene resin, to carry out the ethylenation of quinoline $N$-oxides (Eq. 31) [81]. Recycling the catalyst showed a catalytic efficiency preserved for three consecutive runs. In contrast to intermediates of Scheme 8, the authors proposed the coordination of the oxygen of the substrate to palladium leading to $\mathbf{9 A}$ followed by $\mathrm{C}-\mathrm{H}$ activation and cleavage of the $\mathrm{N}-\mathrm{O}$ bond to afford 9B (Scheme 9). Subsequent insertion of the alkene into the C-Pd bond would give 9C. According to the authors, a $\beta$-H elimination from 9C delivers the product. We suspect the involvement of the chloride or oxygen anion of the plausible intermediate $\mathbf{9 C}$ in the $\mathrm{H}$ elimination, leading with $\mathrm{HCl}$ to water and regeneration of the catalyst.

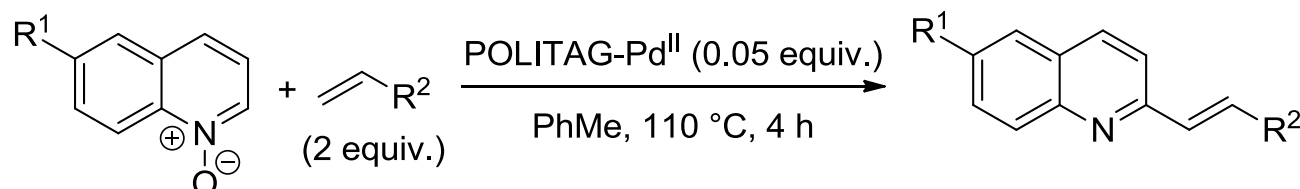

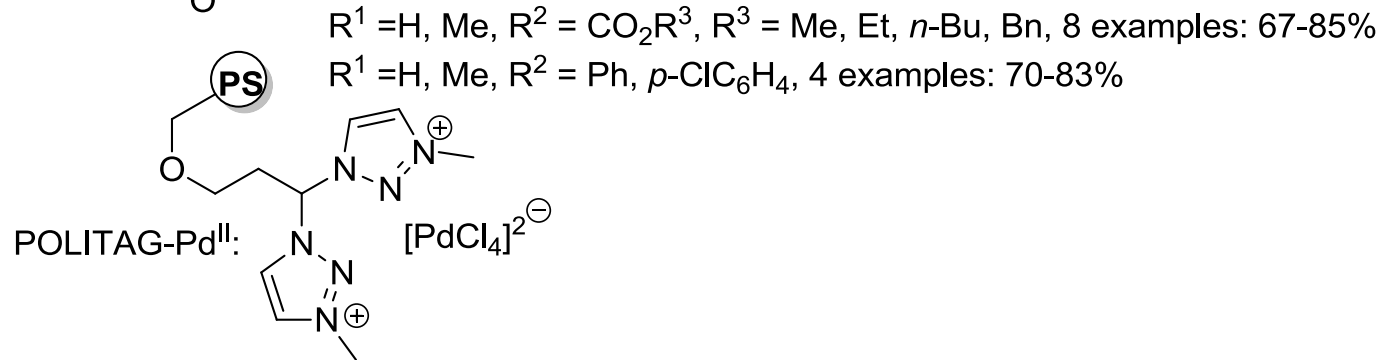

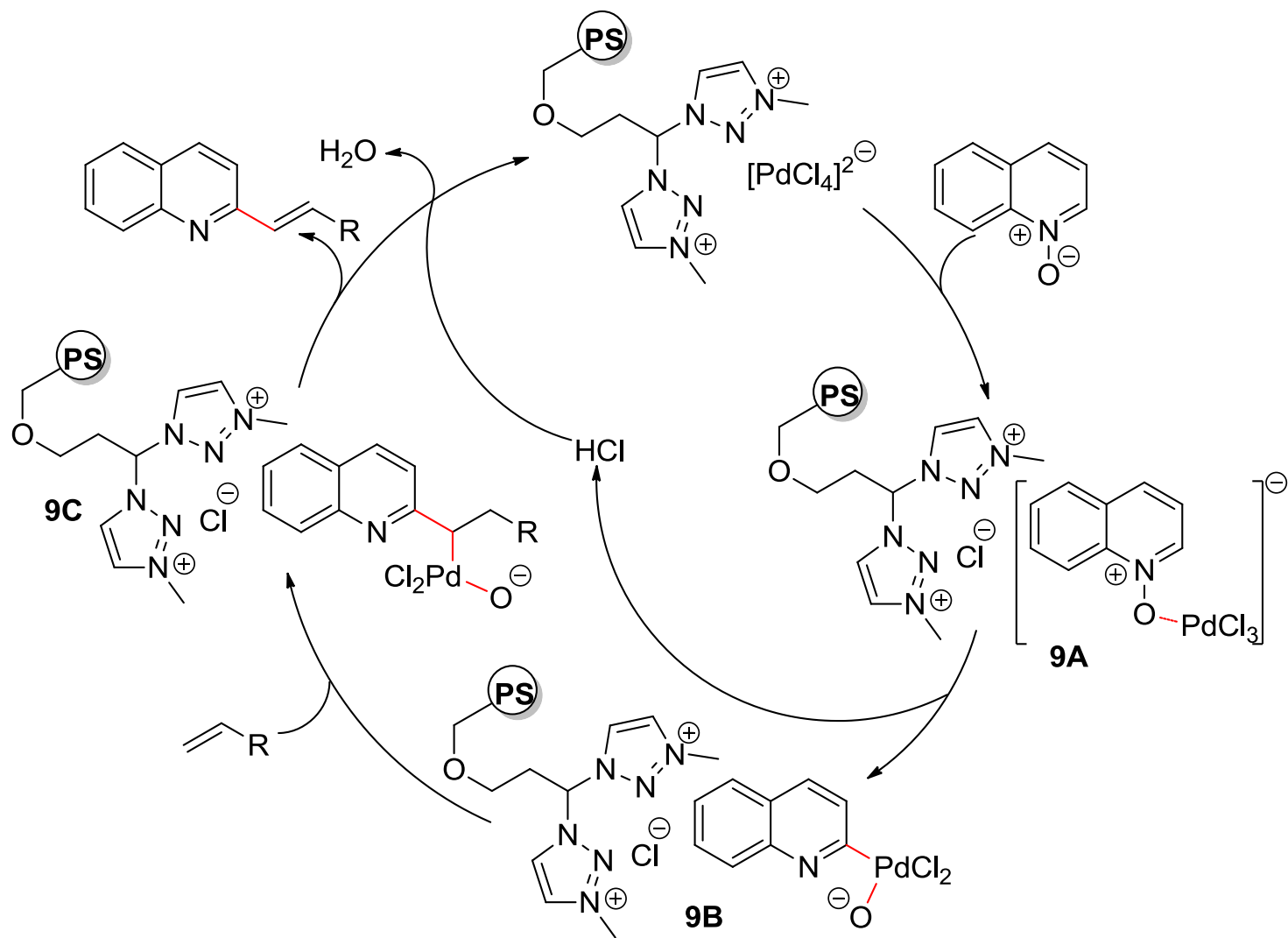

Scheme 9. Vaccaro's mechanism of the DHR of quinoline $N$-oxides.

The $\mathrm{C} 2$ regioselective $\mathrm{C}-\mathrm{H}$ alkenylation of quinoline $\mathrm{N}$-oxide (Eqs 30 and 31 ) is rather surprising since reaction of this substrate with stoichiometric $\mathrm{PdCl}_{2}$ arose in $\mathrm{C} 8$ position leading to the chloride-bridged palladacycle dimer 10A (Scheme 10) [82]. Treatment of 10A with triphenylphosphine produced 10B, which the structure has been confirmed by single-crystal X-ray diffraction. Moreover, $\mathrm{Pd}(\mathrm{OAc})_{2}$ also led to $\mathrm{C} 8-\mathrm{H}$ activation of quinoline $\mathrm{N}$-oxide [80]. The C2 attribution to the substituted position of the DHR products of quinoline $\mathrm{N}$-oxide seems nevertheless adequate. Indeed, the ${ }^{1} \mathrm{H}$ and ${ }^{13} \mathrm{C}$ NMR spectra and chemical shifts attributed to the quinoline $\mathrm{N}$ - 
oxide/butyl acrylate cross-coupling product (Eq. 31) [81] are quasi-identical to those of (E)-butyl 3-(quinolin-2yl)acrylate obtained from quinolone and butyl acrylate under Ma and Huang conditions (Eq. 21) [18].

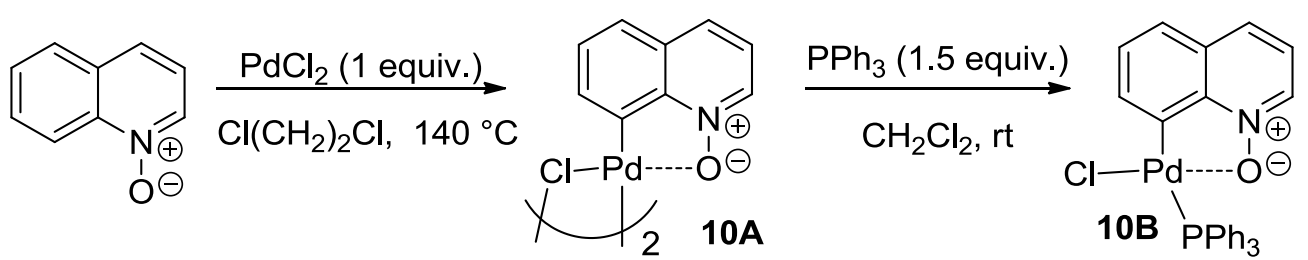

Scheme 10. Pd-mediated C8-H activation of quinoline $\mathrm{N}$-oxide.

\section{O-arenes}

\subsection{Pyrones}

The C3 alkenylation procedure of 4-hydroxypyridin-2(1H)-one (Eq.32) was also effective for the DHR of 6-methyl-2H-pyran-2-ones bearing an hydroxyl, chloride or methoxy substituent in $\mathrm{C} 4$ position (Eq. 32) [60]. Use of DMSO as co-solvent was determinant for good yields.

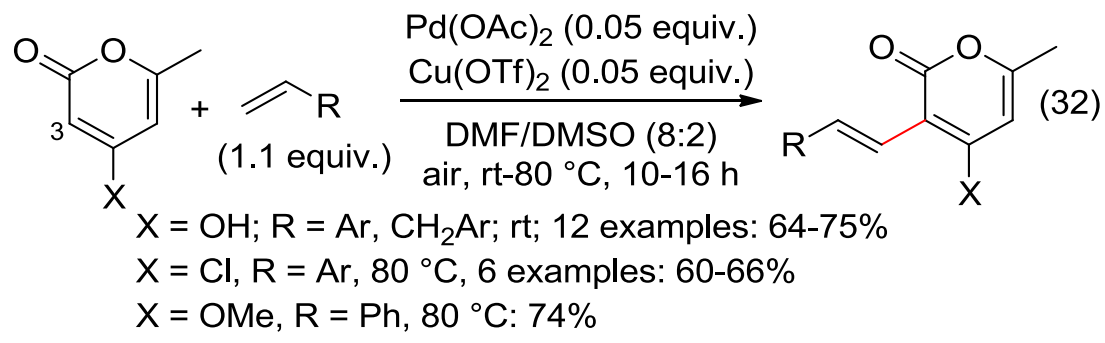

\subsection{Chromen-4-ones}

$\mathrm{Pd}^{\mathrm{II}}$-catalyzed alkenylation of chromen-4-ones arose in fair to high yields in pivalic acid containing $\mathrm{Cu}(\mathrm{OAc})_{2}$ and $\mathrm{Ag}_{2} \mathrm{CO}_{3}$ (Eq. 33) [19]. Use of both pivalic acid and base were required for an effective procedure. According to Hong's team, the regeneration of the catalyst is essentially due to $\mathrm{Cu}(\mathrm{OAc})_{2}$, while $\mathrm{Ag}_{2} \mathrm{CO}_{3}$ mainly functions as a base. Indeed, switching to $\mathrm{K}_{2} \mathrm{CO}_{3}$ led to a limited yield decrease.<smiles>[R]C(=C)C([R])[R]</smiles><smiles>[R]C([R])=Cc1c([R])oc2ccc([R])cc2c1=O</smiles>

$$
\begin{aligned}
& R^{1}=R^{2}=H\left\{\begin{array}{r}
R^{4}=\mathrm{H} ; R^{3}=\mathrm{CO}_{2} \mathrm{R}, \mathrm{COMe}, \mathrm{COH}, \mathrm{CONMe}_{2}, \mathrm{SO}_{2} \mathrm{Ph}, \\
\quad \mathrm{PO}(\mathrm{OEt})_{2}, \mathrm{CN}, \mathrm{Ph} ; 10 \text { examples: } 46-94 \% \\
\mathrm{R}^{4}=\mathrm{H}, \mathrm{R}^{3}=\mathrm{CO}_{2} n-\mathrm{Bu}: 94 \%{ }^{\mathrm{a}} \\
\mathrm{R}^{4}=\mathrm{Me}, \mathrm{R}^{3}=\mathrm{CO}_{2} \mathrm{Me}: 52 \% \\
\mathrm{R}^{4}-\mathrm{R}^{3}=\mathrm{CO}_{2} \mathrm{CH}_{2} \mathrm{CH}_{2}: 63 \%
\end{array}\right. \\
& \mathrm{R}^{1}=\mathrm{Ph}, \mathrm{R}^{2}=\mathrm{R}^{4}=\mathrm{H}, \mathrm{R}^{3}=\mathrm{CO}_{2} n-\mathrm{Bu}: 52 \% \\
& \mathrm{R}^{1}=\mathrm{R}^{4}=\mathrm{H}, \mathrm{R}^{3}=\mathrm{CO}_{2} n-\mathrm{Bu}, \mathrm{R}^{2}=6-\mathrm{Me}, 6-\mathrm{NO}_{2}, 6-\mathrm{Br}, 7-\mathrm{OMe}: 78-93 \% \\
& \text { aWith } \mathrm{K}_{2} \mathrm{CO}_{3} \text { instead of } \mathrm{Ag}_{2} \mathrm{CO}_{3} \text { in } t-\mathrm{BuCO}_{2} \mathrm{H}(72 \%) \text {, } \mathrm{AcOH}(31 \%)^{b} \text {, } \\
& \mathrm{CF}_{3} \mathrm{CO}_{2} \mathrm{H}(18 \%), \mathrm{EtCO}_{2} \mathrm{H}(37 \%), \mathrm{PhCO}_{2} \mathrm{H} \text { (trace) }
\end{aligned}
$$

Subsequently, Hong's team carried out the DHR of chromen-4-ones with quinones (Eq. 34), $\mathrm{N}$ methylmaleimide (Eq. 35) and 1,4-naphthoquinone using $\mathrm{AgOAc}$ instead of the $\mathrm{Cu}(\mathrm{OAc})_{2} / \mathrm{Ag}_{2} \mathrm{CO}_{3}$ mixture, and pivalic acid as additive instead of solvent [83]. According to the authors, the role of $\mathrm{AgOAc}$ is to regenerate the 
catalytic species. A large excess of the quinone being required for fair yields, we suspect its participation in the catalyst recycling [58,59].

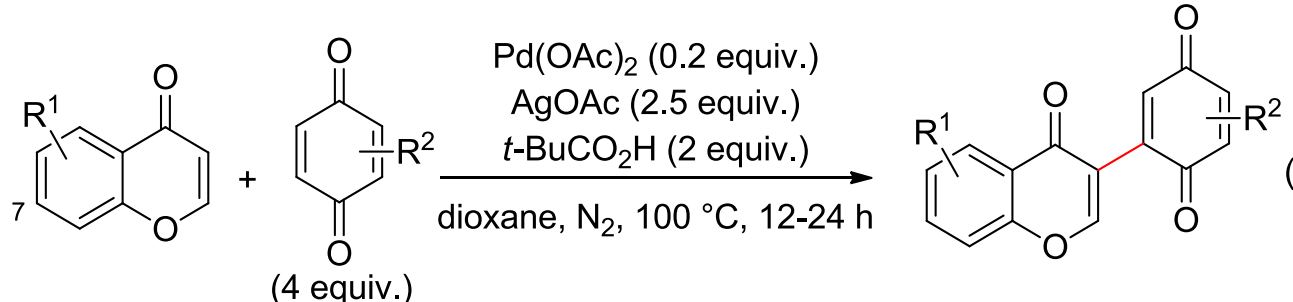

$\mathrm{R}^{1}=\mathrm{H}, 6-\mathrm{Me}, 6-\mathrm{NO}_{2}$, 6-Br, 6-Cl, 6-F, 7-OH, 7-OTf, 7-OAc, 7-OMe;

$\mathrm{R}^{2}=\mathrm{H}, \mathrm{Me}, t-\mathrm{Bu}, \mathrm{OMe}, \mathrm{Br}, \mathrm{Cl}, \mathrm{Ph}, \mathrm{Cy} ; 18$ examples: 55-93\%<smiles>Cc1ccc2c(c1)C(=O)C=[C+]O2</smiles><smiles>Cc1ccc2occ(C3=CC(=O)N(C)C3=O)c(=O)c2c1</smiles>

Hong's team also performed the efficient domino alkenylation/cyclization reactions depicted in Eq. 36 using catalytic amounts of $\mathrm{Pd}(\mathrm{acac})_{2}$ and $\mathrm{Al}_{2} \mathrm{O}_{3}$ in dioxane containing over-stoichiometric amounts of both $\mathrm{Cu}(\mathrm{OAc})_{2}$ and $\mathrm{Cs}_{2} \mathrm{CO}_{3}$ [84]. Yields decreased with other Pd catalysts, oxidants, bases or absence of $\mathrm{Al}_{2} \mathrm{O}_{3}$. According to the authors, the reaction involves the $\mathrm{C} 3$ alkenylated intermediate which undergoes a Michael-type addition favored by $\mathrm{Al}_{2} \mathrm{O}_{3}$.

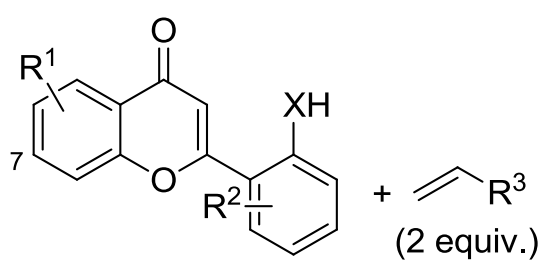

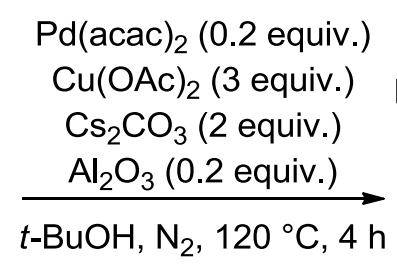<smiles>[R]CC([X])c1c([R])oc2ccccc2c1=O</smiles>

$$
\begin{aligned}
& X=O\left\{\begin{array}{r}
R^{1}=\mathrm{H}, 6-\mathrm{Me}, 6-\mathrm{Cl}, 6-\mathrm{F}, 7-\mathrm{Me}, 7-\mathrm{F} ; \mathrm{R}^{2}=\mathrm{H}, \mathrm{Cl}, \mathrm{Br} ; \mathrm{R}^{3}=\mathrm{CO}_{2} \mathrm{R}, \mathrm{COMe}, \\
\quad \mathrm{COPh}, \mathrm{CONMe}{ }_{2}, \mathrm{PO}(\mathrm{OEt})_{2} ; 14 \text { examples: } 51-83 \% \\
\mathrm{R}^{1}=\mathrm{R}^{2}=\mathrm{H} ; \mathrm{R}^{3}=\mathrm{CO}_{2} n-\mathrm{Bu}: 74 \%{ }^{\mathrm{a}}
\end{array}\right. \\
& \mathrm{X}=\mathrm{NTs} ; \mathrm{R}^{1}=\mathrm{R}^{2}=\mathrm{H} ; \mathrm{R}^{3}=\mathrm{CO}_{2} n-\mathrm{Bu}: 62 \%
\end{aligned}
$$

${ }^{a}$ In the absence of $\mathrm{Al}_{2} \mathrm{O}_{3}: 63 \%$.

Bäckvall's conditions used for the DHR of $N$-methylpyridin-2(1H)-one (Eq. 13) led to the cross-coupling of chromen-4-one with methylacrylate in a yield which also decreased when pivalic acid was exchanged for an AcOH/DMA mixture (Eq. 37) [57].

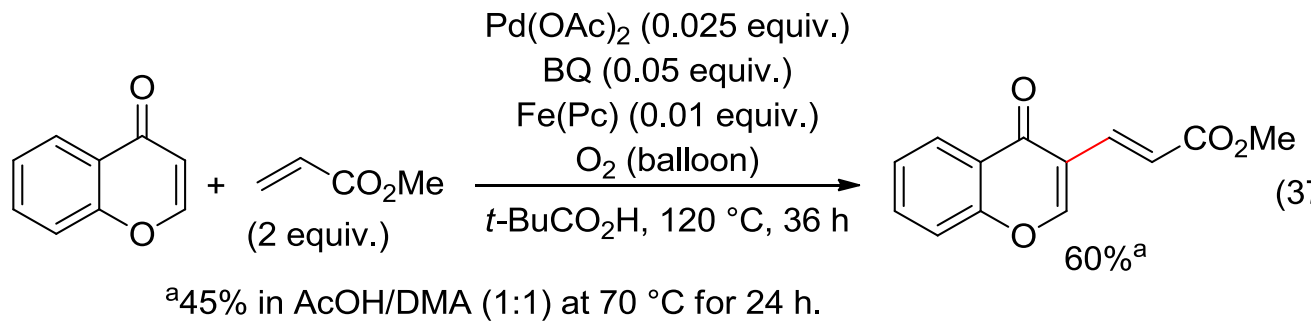


A procedure close to that used for the dehydrogenation/dehydrogenative Heck reaction of $\mathrm{N}$-substituted 2,3-dihydroquinolin-4(1H)-ones (Eq. 25) has led to the corresponding domino reaction of chroman-4-ones (Eq. 38) [70].

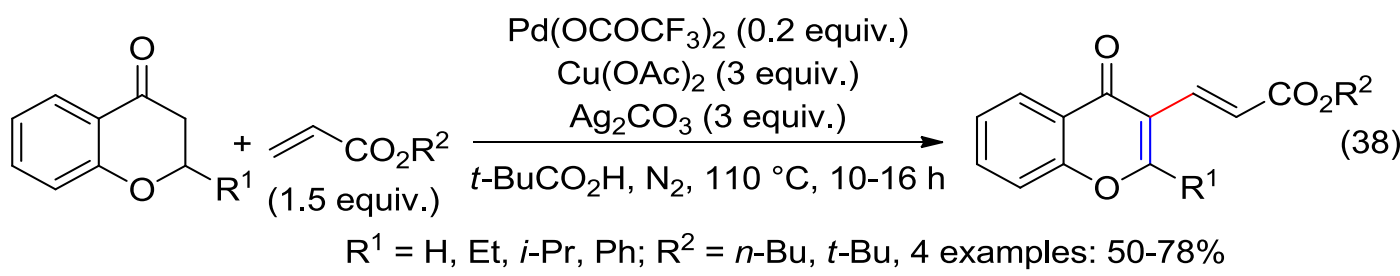

\section{3. $2 H$-chromen-2-ones ${ }^{6}$}

The Pd(OCOt-Bu $)_{2}$-catalyzed method used for DHRs of 7-methoxy-1-methylquinolin-2(1H)-one (Eq. 27) was effective for the $\mathrm{C} 3$ olefination of $2 \mathrm{H}$-chromen-2-ones (Eqs 39 and 40) [71]. Regeneration of the catalyst with $\mathrm{Cu}(\mathrm{OAc})_{2}$ instead of oxygen atmosphere as well as absence of the base were detrimental to the yields (Eq. 39). Hong's team proposed the participation of the oxygen atom in the formation of the C-Pd bond to provide 11A (Scheme 11). Subsequent insertion of the olefin followed by $\beta-\mathrm{H}$ elimination affords the product.

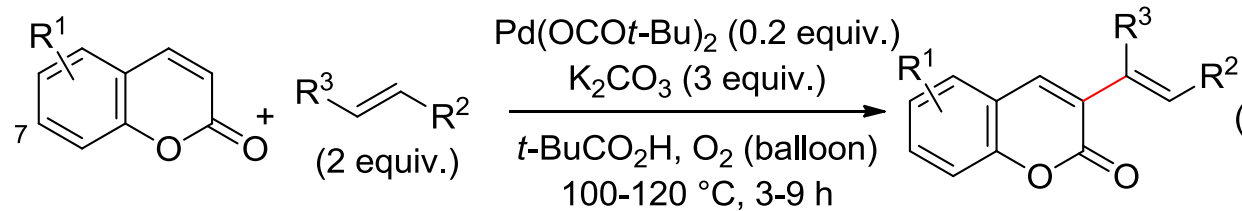

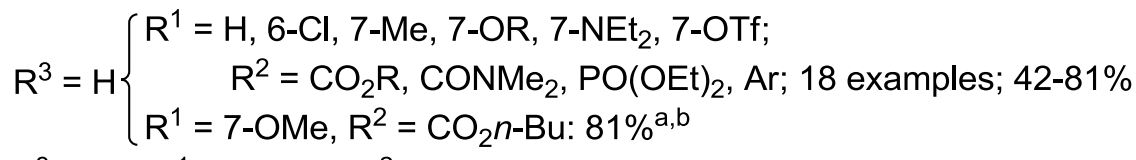

$\mathrm{R}^{3}=\mathrm{Ph}, \mathrm{R}^{1}=7-\mathrm{OMe}, \mathrm{R}^{2}=\mathrm{CO}_{2} \mathrm{Me}: 52 \%$

${ }^{a}$ With $\mathrm{Cu}(\mathrm{OAc})_{2}$ (3 equiv.) instead of $\mathrm{O}_{2}: 40 \%$

aln absence of $\mathrm{K}_{2} \mathrm{CO}_{3}$ with $\mathrm{Cu}(\mathrm{OAc})_{2}$ (3 equiv.) instead of $\mathrm{O}_{2}: 20 \%$.

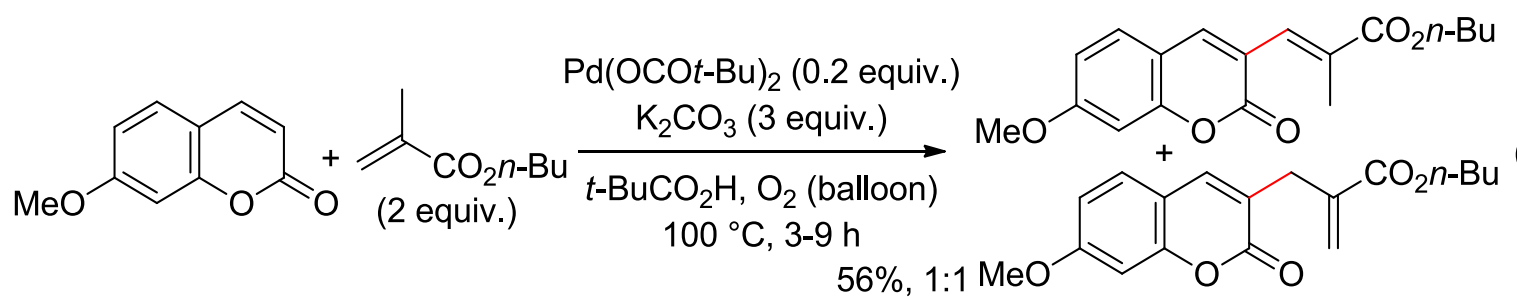

\footnotetext{
${ }^{6}$ Other appellation: coumarins.
} 


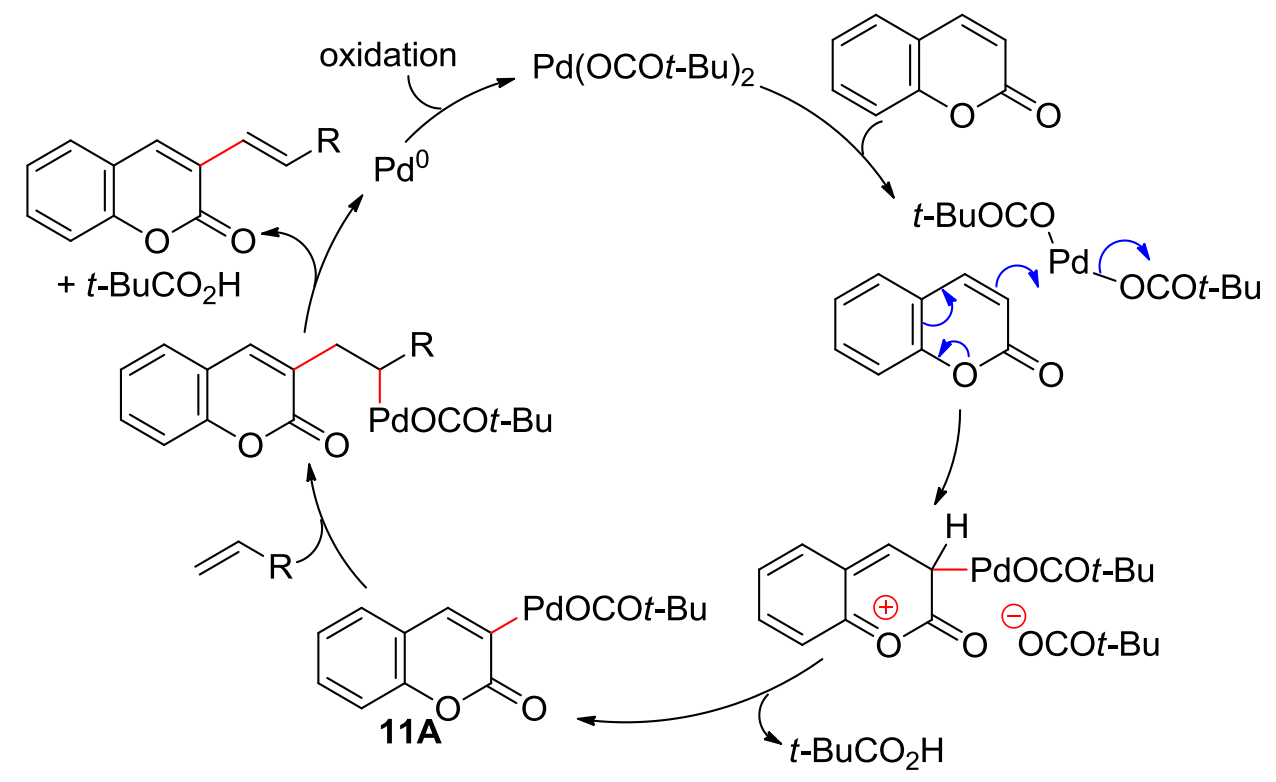

Scheme 11. The plausible participation of the oxygen ring in the DHR of $2 \mathrm{H}$-chromen-2-ones. Adapted from [70].

In contrast to $N$-methylpyridin-2(1H)-one (Eq. 13) and chromen-4-one (Eq. 37), Bäckvall's procedure did not mediated the DHR of $2 \mathrm{H}$-chromen-2-one with methylacrylate (Eq. 41) [57].

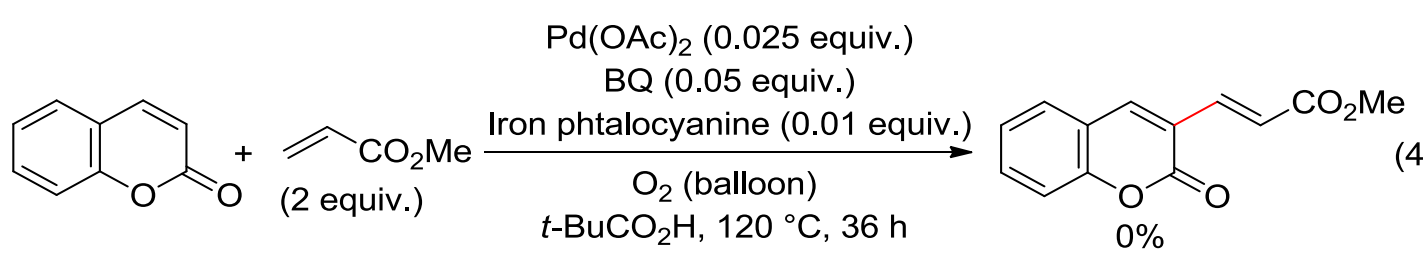

The domino alkenylation/cyclization reaction of 2-aryl-4H-chromen-4-ones (Eq. 36) also arose from the corresponding 4-aryl-2H-chromen-2-ones, but under slight modified experimental conditions for fair yields (Eq. 42) [84]. The presence of $\mathrm{Al}_{2} \mathrm{O}_{3}$.was not required for an effective cyclization step.

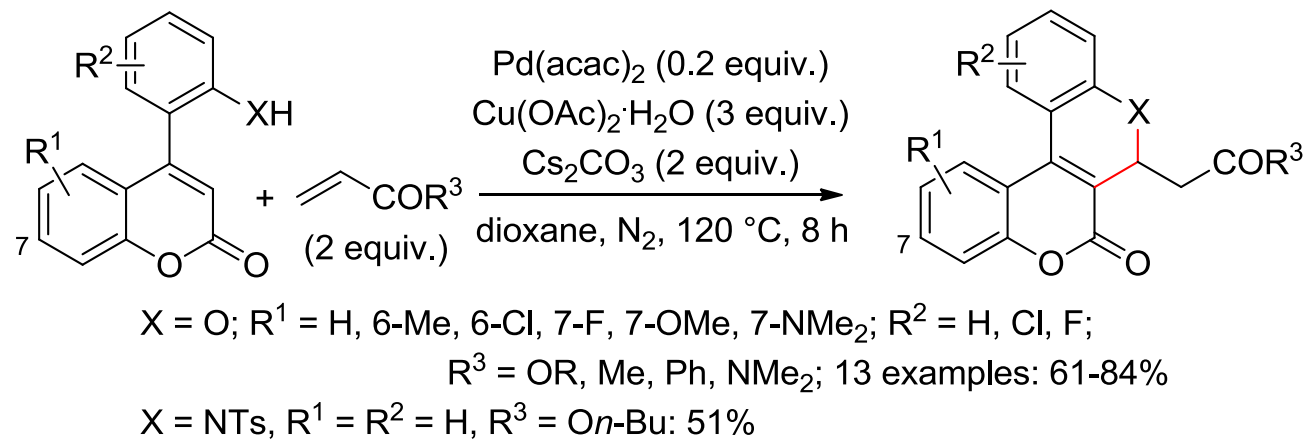

Domino alkenylation/cyclization reactions also occurred from 4-hydroxy- $2 H$-chromen-2-ones but were limited to styrenes and stilbenes (Eq. 43) [85]. The experimental conditions were rather unusual and required catalytic $\mathrm{Pd}\left(\mathrm{OCOCF}_{3}\right)_{2}$ in aerated chlorobenzene for good yields. The expected adduct was not formed with 1octene (Eq. 43), while cleavage of the C- $\mathrm{CO}_{2} \mathrm{Me}$ bond happened with methyl methacrylate (Eq. 44). 


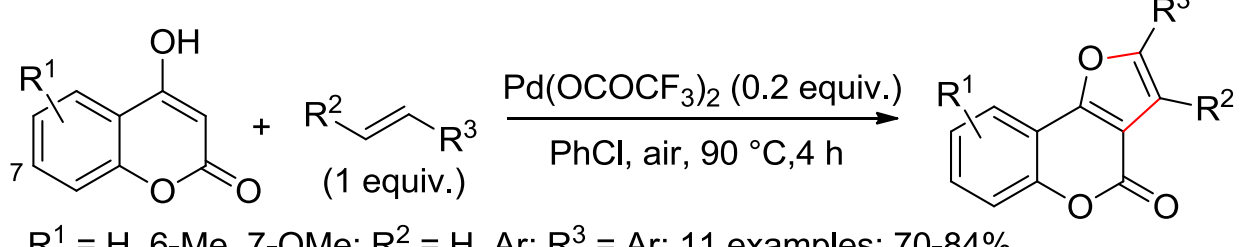

$\mathrm{R}^{1}=\mathrm{H}, 6-\mathrm{Me}, 7-\mathrm{OMe} ; \mathrm{R}^{2}=\mathrm{H}, \mathrm{Ar} ; \mathrm{R}^{3}=\mathrm{Ar} ; 11$ examples: $70-84 \%$

$\mathrm{R}^{1}=\mathrm{R}^{2}=\mathrm{H} ; \mathrm{R}^{3}=\mathrm{Ph}\left(81 \%^{\mathrm{a}, \mathrm{b}}\right), n-\mathrm{C}_{6} \mathrm{H}_{13}(0 \%)$

a'Other solvents: PhMe (60\%), dioxane (40\%), DCE (25\%), DMSO $(20 \%)$, DMF $(0 \%)$

bOther catalysts: $\mathrm{Pd}(\mathrm{OAc})_{2}(69 \%), \mathrm{PdCl}_{2}(30 \%), \mathrm{Pd}_{2}(\mathrm{dba})_{3}(45 \%)$.<smiles></smiles>

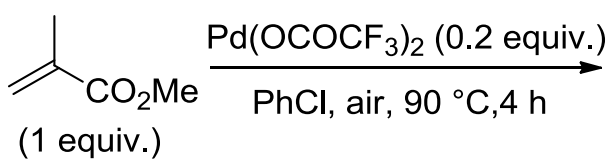<smiles>Cc1cc2c(=O)oc3ccccc3c2o1</smiles>

The DHR of a polycyclic substrate such as xanthoxine, which contains both five and six membered heteroaromatic rings, selectively arose at the level of the furanyl ring (Eq. 45) [86].<smiles>CCOC(=O)C=CC=Cc1cc2cc3ccc(=O)oc3c(OC)c2o1</smiles>

\section{4. $\mathrm{N}, \mathrm{N}$-arenes}

\subsection{Pyrimidines}

The experimental conditions disclosed in Eqs 1 and 4-6 for the DHRs of pyridines led to selective C5 olefination of pyrimidine (Eqs 46 [13] and 47 [23]).
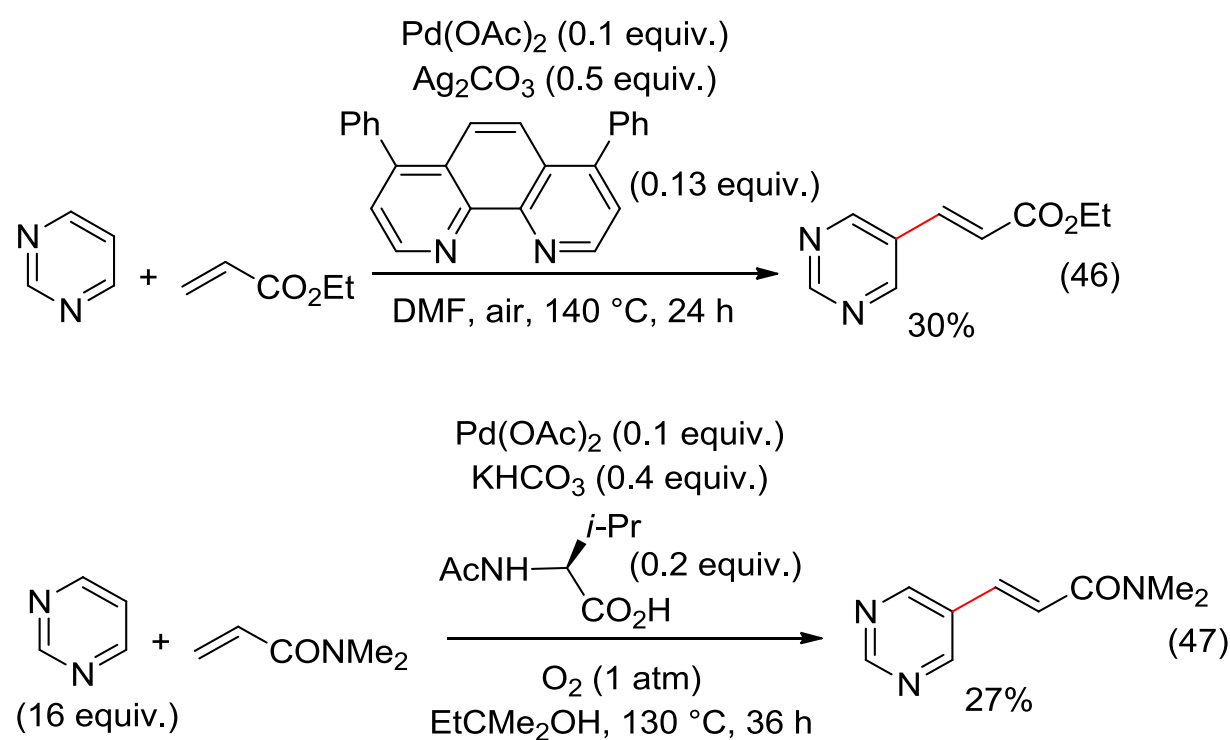
Using $\mathrm{Pd}(\mathrm{OAc})_{2} / \mathrm{Cu}(\mathrm{OAc})_{2} \mathrm{H}_{2} \mathrm{O} / \mathrm{Ag}_{2} \mathrm{CO}_{3}$ in aerated $\mathrm{AcOH}, N$ - $(t$-butyl)pyrimidin-2-amine underwent cross-coupling with acrylates (Eq. 48) [87]. Performing the reaction in the absence of acrylates in perdeuterated acetic acid led to deuterium exchange at $\mathrm{N}$ and $\mathrm{C} 5$ positions. Moreover, arylation experiments showed the formation of only traces of cross-coupling when the $\mathrm{NH}$ of the substrate was protected with a methyl group. Consequently, Maji's team proposed the participation of the NH group in the mechanism of the DHR (Scheme 12). Interaction of the substrate with catalyst and base affords intermediate $12 \mathrm{~A}$ which, according to the authors, undergoes base-mediated $\mathrm{H}$ abstraction leading to 12B. Subsequent insertion of the olefin into the C-Pd bond followed by $\beta$-H elimination gives the product.

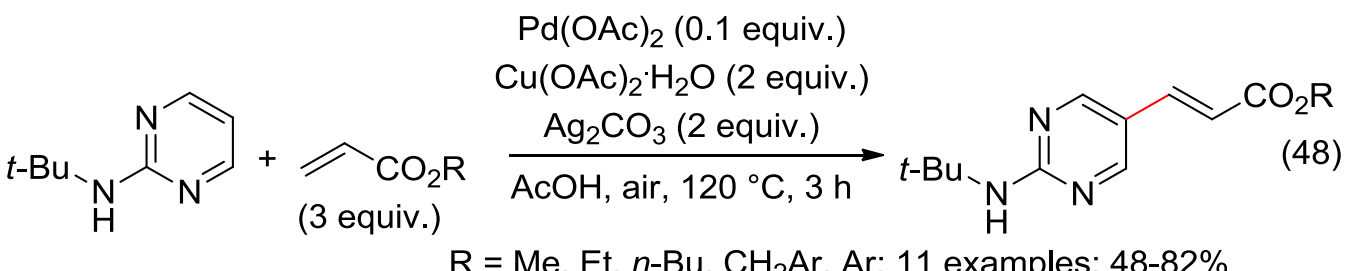

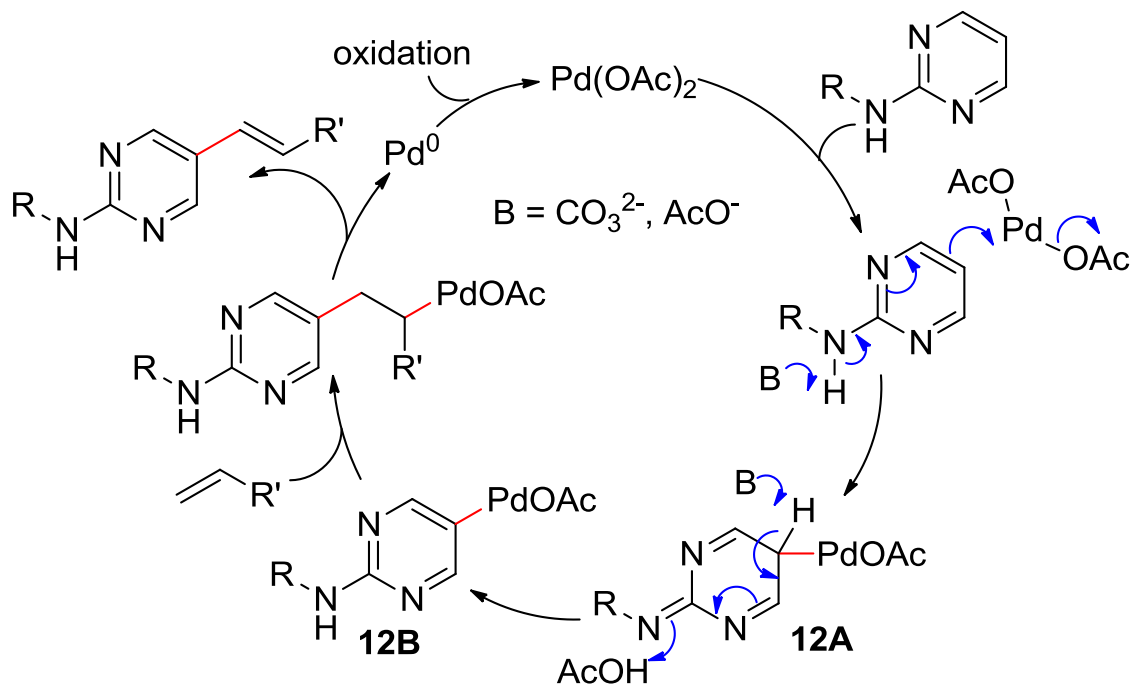

Scheme 12. Unusual intermediate of the DHR of $N$-( $t$-butyl)pyrimidin-2-amine. Adapted from [87].

\subsection{Pyrazines}

The Ma and Huang procedure of the DHR of pyridines (Eq. 2) was also used for the alkenylation of 2,6dimethylpyrazine (Eq. 49) [18].

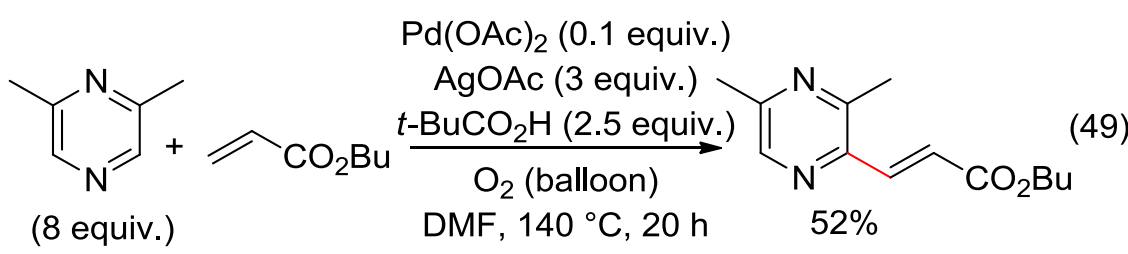

\subsection{Pyrimidin-4-ones}

Two aerobic procedures have been reported for the DHR of $4 H$-pyrido[1,2- $a$ ]pyrimidin-4-ones. The first one due to Wang, Cao and co-workers, used catalytic $\mathrm{Pd}(\mathrm{OAc})_{2}$ with 0.5 equiv. of $\mathrm{AgOAc}$ at $110^{\circ} \mathrm{C}$ in $\mathrm{DMF}$ (Eq. 50) [88]. The yields were dramatically reduced with $\mathrm{Cu}(\mathrm{OAc})_{2}$ or only oxygen as the oxidant. Subsequently, Liang's team disclosed experimental conditions used with 2-methyl-4H-pyrido[1,2-a]pyrimidin-4-ones (Eq. 51) [20]. Carried out in the presence of pivalic acid, these DHRs did not required the use of AgOAc as co-oxidant. 
Only one substrate was common to the two reports, leading to $(E)$-2-methyl-3-styryl- $4 H$-pyrido[1,2-a]pyrimidin4-one in 84 and 73\% yields under conditions of Eqs 50 and 51, respectively.

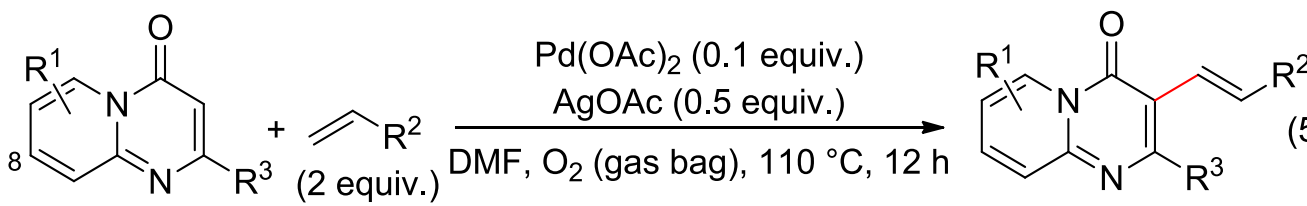

$$
R^{3}=H\left\{\begin{array}{l}
R^{1}=\mathrm{H} ; \mathrm{R}^{2}=\mathrm{CO}_{2} \mathrm{R}, \mathrm{COMe}, \mathrm{CONHt}-\mathrm{Bu}, \mathrm{Ar} ; 13 \text { examples: } 75-92 \% \\
\mathrm{R}^{1}=6-\mathrm{Me}, 7-\mathrm{Me}, 7-\mathrm{F}, 8-\mathrm{Me}, 8-\mathrm{Cl}, 9-\mathrm{Me} ; \mathrm{R}^{2}=\mathrm{CO}_{2} \mathrm{R}, \mathrm{Ph} ; 9 \text { examples: } 73-85 \% \\
\mathrm{R}^{1}=7-\mathrm{NO}_{2}, \mathrm{R}^{2}=\mathrm{CO}_{2} t-\mathrm{Bu}: 0 \%
\end{array}\right.
$$

$\mathrm{R}^{3}=\mathrm{Me} ; \mathrm{R}^{1}=\mathrm{H}, 7-\mathrm{F}, 7-\mathrm{Cl}, 8-\mathrm{Me} ; \mathrm{R}^{2}=\mathrm{CO}_{2} t-\mathrm{Bu}, \mathrm{Ph} ; 8$ examples: $75-84 \%$

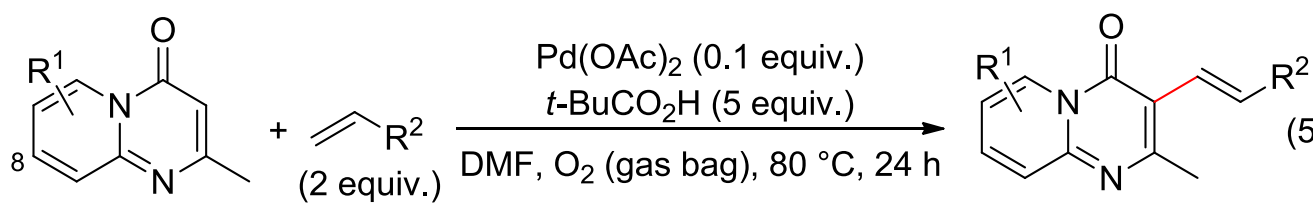

$\mathrm{R}^{1}=\mathrm{H} ; \mathrm{R}^{2}=\mathrm{CO}_{2} \mathrm{R}, \mathrm{CONHt}$-Bu, Ar; 11 examples: 63-83\%

$\mathrm{R}^{1}=7-\mathrm{Me}, 7-\mathrm{F}, 7-\mathrm{Cl}, 8-\mathrm{Me}, 9-\mathrm{Me} ; \mathrm{R}^{2}=\mathrm{CO}_{2} \mathrm{R}, \mathrm{Ph} ; 10$ examples: $59-75 \%$

\subsection{Uracils ${ }^{7}$}

The above Bäckvall experimental conditions above used for the DHR of $N$-methylpyridin-2(1H)-one and chromen-4-one with methylacrylate (Eqs 13 and 37) were also effective for the regioselective C5 olefination of 1,3-dimethyluracil (Eq. 52) [57].

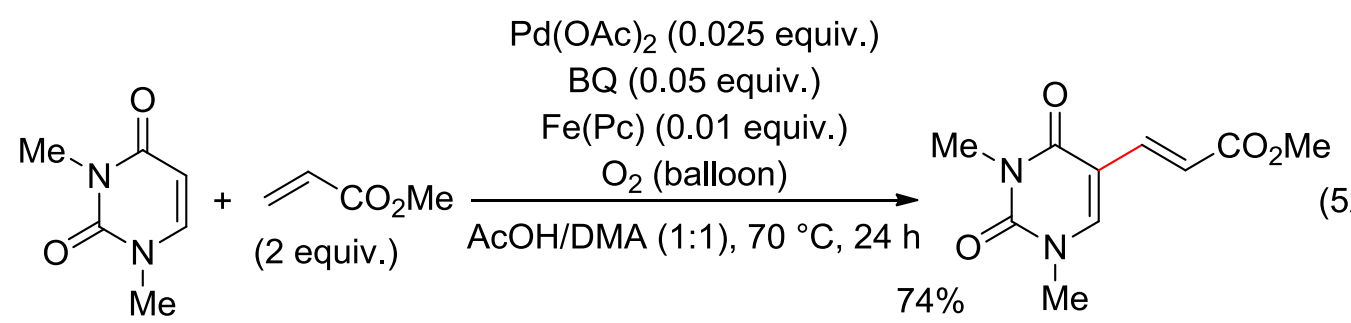

Another aerobic regioselective method, which used catalytic $\mathrm{Pd}(\mathrm{OAc})_{2}$ and excesses of both $\mathrm{AgOAc}$ and $t-\mathrm{BuCO}_{2} \mathrm{H}$ in DMF, provided fair to high yields of various $\mathrm{C} 5$ olefinated $\mathrm{N}$-substituted uracils (Eq. 53) [89]. No DHR was observed when one of the two nitrogen atoms was unsubstituted. Use of $\alpha$-substituted acrylates such as $t$-butyl methacrylate afforded a mixture of conjugated and deconjugated cross-coupling products as well as the cross-coupling adduct stemming from the subsequent DHR of the deconjugated product with the uracil (Eq. 53). Conjugated and deconjugated cross-coupling products were also formed from allyl acetate (Eq. 54). According to Georg and $\mathrm{Yu}$, deprotonation of the uracil is assumed by pivalate as depicted for pyridine in Scheme 2 [89].

\footnotetext{
${ }^{7}$ Other appellation: pyrimidine-2,4(1H,3H)-diones.
} 
(2 equiv.)

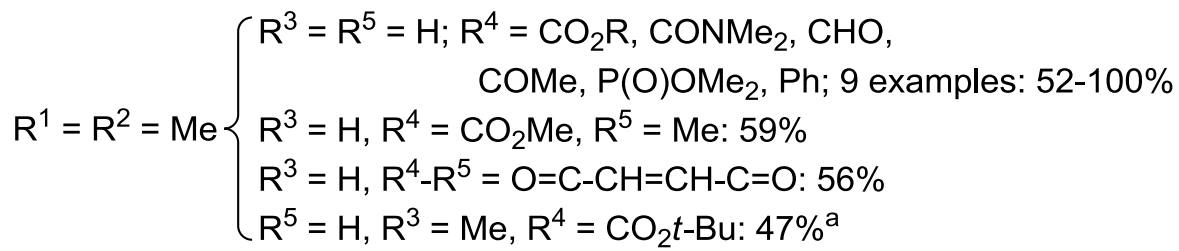

$\mathrm{R}^{1}, \mathrm{R}^{2}=\mathrm{Bn}, \mathrm{MOM}, \mathrm{PMB} \ldots ; \mathrm{R}^{3}=\mathrm{R}^{5}=\mathrm{H} ; \mathrm{R}^{4}=\mathrm{CO}_{2} t-\mathrm{Bu} ; 7$ examples: $66-96 \%$

$R^{3}=R^{5}=H, R^{4}=\mathrm{CO}_{2} t-B u\left\{\begin{array}{l}R^{1}=R^{2}=H: 0 \% \\ R^{1}=P h C O ; R^{2}=H: 0 \% \\ R^{1}=H ; R^{2}=\text { PhCO: } 0 \%\end{array}\right.$

Isomers mixture plus

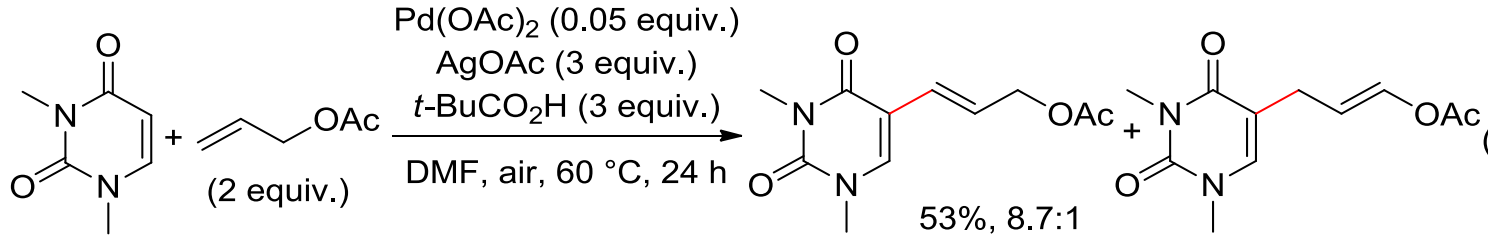

A metal-organic framework, named Cu-MOF-74, has been prepared from 2,5-dihydroxyterephthalic acid and $\mathrm{Cu}\left(\mathrm{NO}_{3}\right)_{2} \cdot 3 \mathrm{H}_{2} \mathrm{O}$ in DMF/i-PrOH by Cirujano, De Vos and co-workers [90]. The authors disclosed that addition of Cu-MOF-74 to $\mathrm{Pd}(\mathrm{OAc})_{2}$ improved the lifetime of the catalyst, and used the combination for the DHR of uracil, at $30^{\circ} \mathrm{C}$ in DMSO with $t$-BuOOH as the oxidant (Eq. 55).

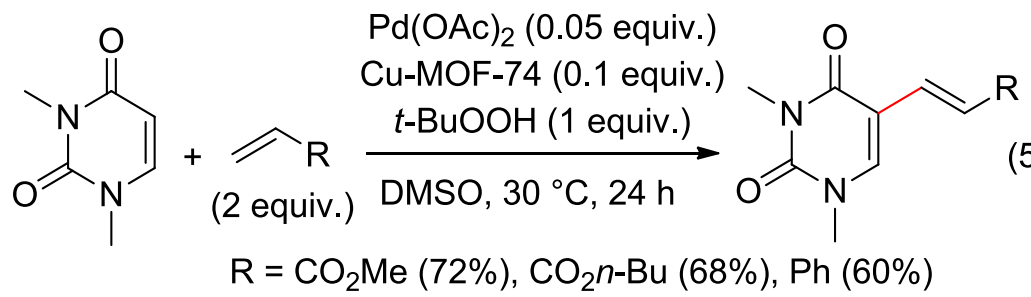

The Hong experimental conditions of above dehydrogenation/dehydrogenative Heck reactions (Eqs 25 and 38) have been used for the corresponding transformation of 1,3-dimethyldihydropyrimidine-2,4(1H,3H)dione (Eq. 56) [70].<smiles>CN1C[C+](C=CC(=O)OC(C)(C)C)CC(=O)N(C)C1=O</smiles><smiles>Cn1cc(/C=C/C(=O)OC(C)(C)C)c(=O)n(C)c1=O</smiles>

\subsection{Quinoxaline $N$-oxide}


The DHR of quinoxaline N-oxide with styrene under Chang's conditions used for the cross-coupling with acrylates [91] led to the expected compound in a modest yield [92]. Emery and co-workers improved the efficiency of the procedure in using a $\mathrm{N}$-protected amino acid (FMoc-Val-OH) and $\mathrm{AgOAc}$ instead of pyridine and $\mathrm{Ag}_{2} \mathrm{CO}_{3}$ (Eq. 57). Yields were however greatly dependent on the styrene substituents and the nature of silver salt. The proposed catalytic cycle was similar to that depicted in Scheme 3.

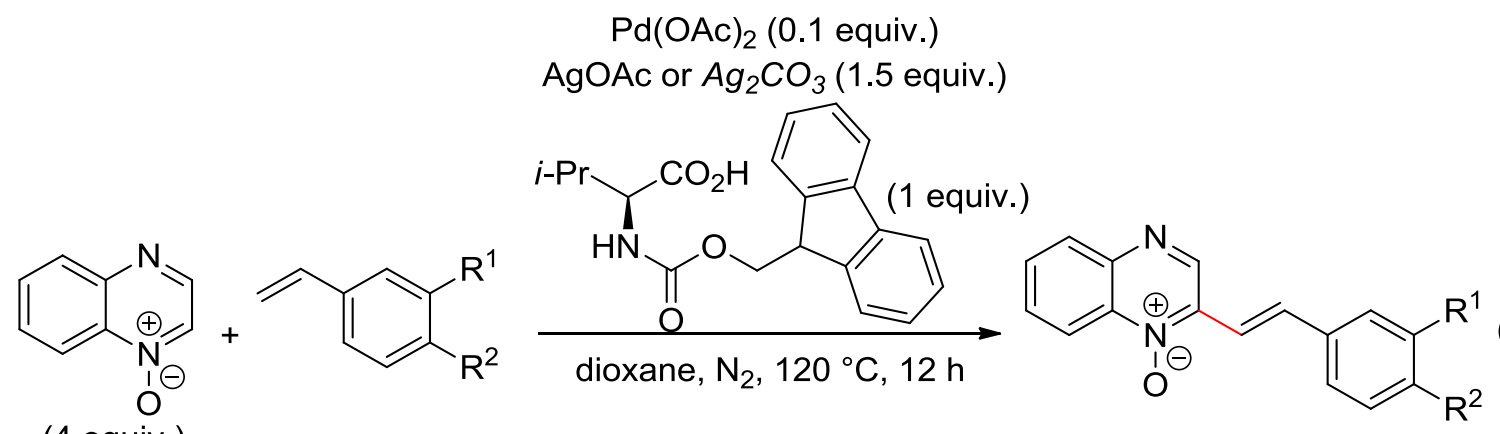

(4 equiv.)

$\mathrm{R}^{1}=\mathrm{H}, \mathrm{R}^{2}=\mathrm{H}\left(85 \%, 75 \%^{\mathrm{a}}\right), \mathrm{CO}_{2} \mathrm{Me}(85 \%, 73 \%), \mathrm{OMe}(42 \%, 84 \%), \mathrm{Br}(46 \%, 32 \%), \mathrm{OAc}(29 \%, 85 \%)$ $\mathrm{R}^{1}=\mathrm{R}^{2}=\mathrm{OMe}(89 \%, 78 \%)$

${ }^{a}$ With pyridine instead of FMoc-Val-OH: $64 \%$.

The Vaccaro procedure (Eq. 31) has also been used for the cross-coupling of quinoxaline N-oxide with acrylates and styrenes (Eq. 58) [81].

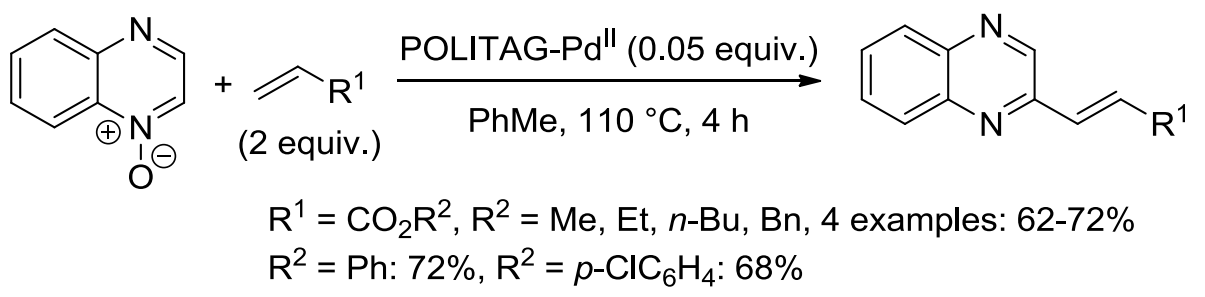

\section{N,O-arene}

In pivalic acid, (4H-benzo[b][1,4]oxazin-4-yl)(phenyl)methanone underwent cross-coupling with benzyl acrylate using copper acetate, silver carbonate and catalytic $\mathrm{Pd}(\mathrm{OAc})_{2}$ (Eq. 59) [93].
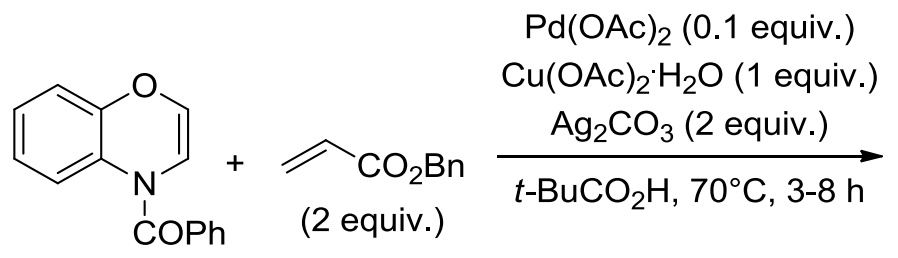<smiles>C[Sb]([13CH3])(=O)c1ccccc1</smiles>

\section{N,S-arenes}

The DHR of $t$-butyl $4 H$-benzo[b][1,4]thiazine-4-carboxylate using the above method occurred in a low yield (Eq. 60) [93].

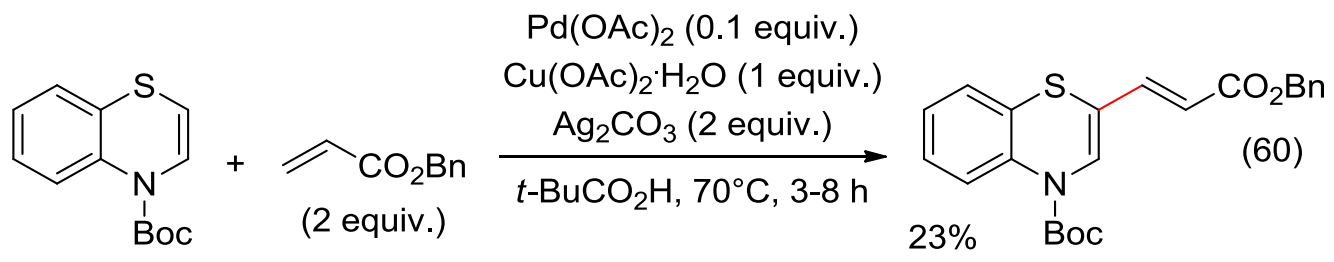




\section{O,P-arenes}

\subsection{4-Phosphachromones}

C3 alkenylation of 4-ethoxy-4H-benzo[b][1,4]oxaphosphinine 4-oxides arose with a variety of activated and unactivated olefins under conditions similar to those of Eqs 59 and 60, except the use of air atmosphere (Eq. 61) [94]. Lee and co-workers showed that both copper acetate and silver carbonate were required for a successful reaction.

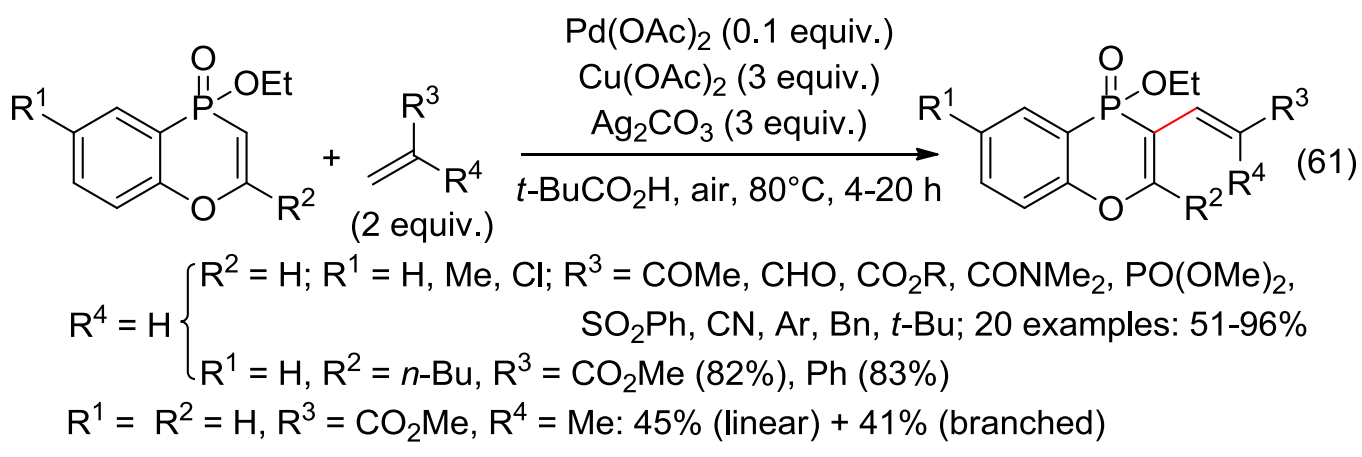

\subsection{Phosphacoumarins}

Lee's team also carried out the DHR of 2-ethoxy-2H-benzo[e][1,2]oxaphosphinine 2-oxides using $\mathrm{AgOAc}$ (Eq. 62) [95] instead of the $\mathrm{Cu}(\mathrm{OAc})_{2} / \mathrm{Ag}_{2} \mathrm{CO}_{3}$ mixture (Eq. 61) for improved yields. The authors suggested the participation of the ring oxygen atom in the formation of the C-Pd bond as previously depicted in Scheme 11 .

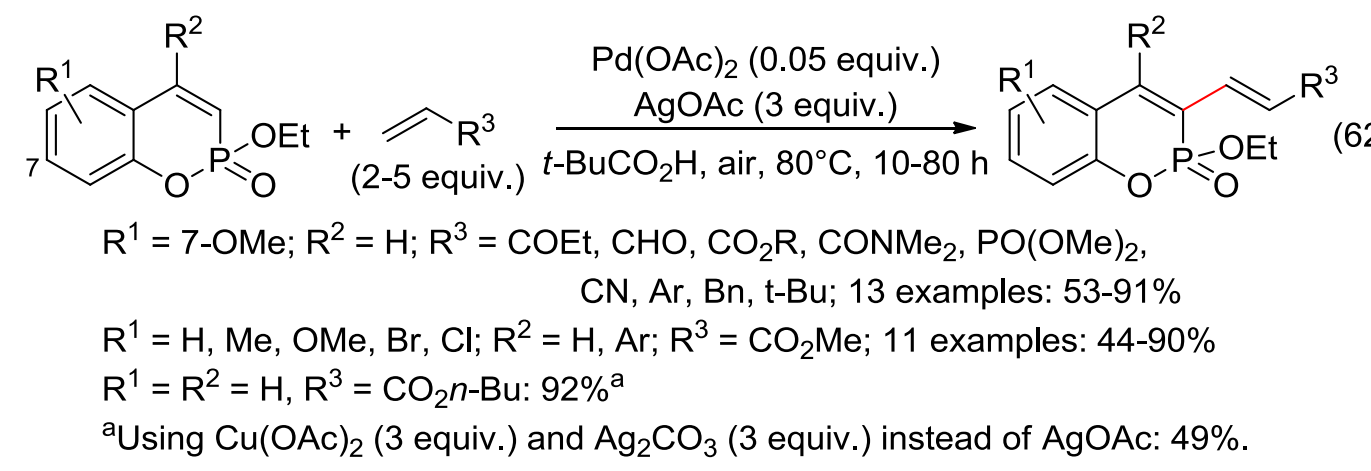

\section{O,S-arenes}

Palladium pivalate in pivalic acid catalyzed the aerobic DHR of sulfocoumarins ${ }^{8}$ (Eq. 63) [96]. Oxygen was superior to other oxidants. Participation of the ring oxygen atom in the formation of the C-Pd bond (Scheme 11) as above suspected [71,95] was assumed by Hong and co-workers.

\footnotetext{
${ }^{8}$ Other appellation: benzo[e][1,2]oxathiine 2,2-dioxides.
} 


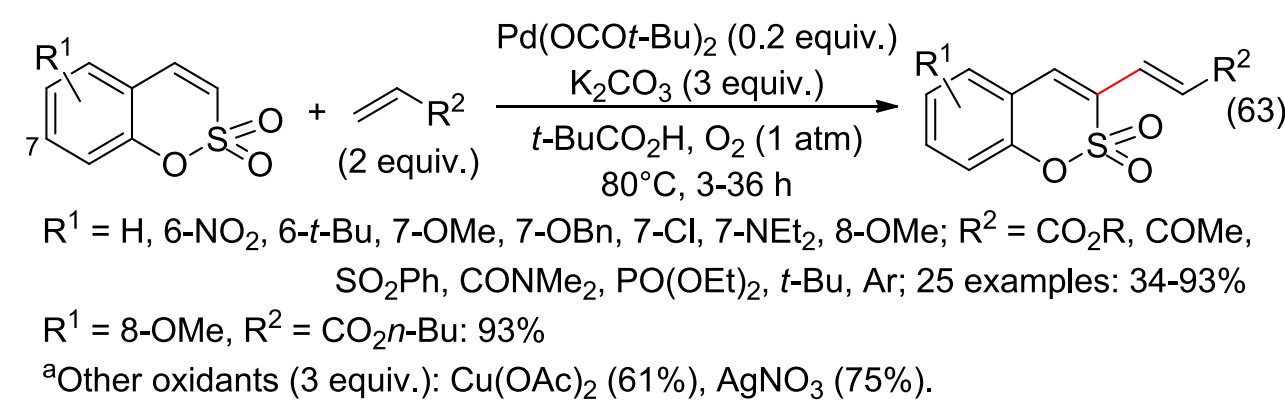

\section{Conclusion}

As above exemplified, effective alkenylation of six membered heteroarenes may occur using the $\mathrm{Pd}^{\mathrm{II}}$ catalyzed DHR procedure. In most cases, no directing group is required to favor the initial palladation and selective transformations. The catalyst activity should be however improved since long reaction times and relatively high temperatures are usually required. In addition, some processes employ large excess of the arenes.

Most catalytic cycles proposed are very discreet on the mechanism of the $\mathrm{C}-\mathrm{H}$ activation of the substrate. This formation of the $\mathrm{C}-\mathrm{Pd}$ bond from the $\mathrm{C}-\mathrm{H}$ bond of arenes has however been the subject of thoroughly computational studies, indicating that species coordinated to the palladium atom may have a key role.

According to the gathered above examples, the pivalate ligand favors the $\mathrm{C}-\mathrm{H}$ cleavage and often increases the efficiency of the DHR. The role of pivalic acid in the Pd-catalyzed reactions is however highly dependent on the experimental conditions. Indeed, a recent report disclosed the reduction of $\mathrm{Pd}^{\mathrm{II}}$ complexes by pivalate [97], that is a reaction which would be unfavorable to the Pd ${ }^{\mathrm{II}}$ chemistry of the DHR process.

The presence of a silver acetate in sub- or over-stoichiometric amount is frequently required for an effective catalytic procedure. In most reports, its role is attributed to the regeneration of the catalytic species while the possibility to form an active $\mathrm{Pd} / \mathrm{Ag}$ heterobimetallic catalyst is not considered.

Whatever the pathways of the $\mathrm{C}-\mathrm{H}$ activation and the cross-coupling reaction, the above olefinations of six membered heteroarenes, which formally arise from the removal of only the molecular hydrogen, afford products which are commonly privileged structures in many biologically active compounds.

\section{References}

1. (a) Heck, R.F. Palladium Reagents in Organic Syntheses Acad. Press: London, 1985, pp 260-268; (b) Tsuji, J. Palladium Reagents and Catalysts, Innovations in Organic Synthesis Wiley: Chichester, 1995, pp 55-59; (c)Tsuji, J. Palladium Reagents and Catalysts, New Perspectives for the 21st Century Wiley: Chichester, 2004; (d) The Mizoroki-Heck Reaction Oestreich, M. Ed., Wiley: Chichester, 2009.

2. (a) Moritani, I.; Fujiwara, Y. Aromatic substitution of styrene-palladium chloride complex. Tetrahedron Lett., 1967, 1119-1122; (b) Fujiwara, Y.; Moritani, I.; Matsuda, M.; Teranishi, S. Aromatic substitution of olefins. IV Reaction with palladium metal and silver acetate. Tetrahedron Lett., 1968, 3863-3865.

3. (a) Mizoroki, T.; Mori, K.; Ozaki, A. Arylation of olefin with aryl iodide catalyzed by palladium. Bull. Chem. Soc. Jpn., 1971, 44, 581; (b) Julia, M.; Duteil, M. Condensation of aromatic halides with olefins catalyzed by palladium(0). Bull. Soc. Chim. Fr., 1973, 2790; (c) Heck, R.F.; Nolley, J.P., Jr. Palladiumcatalyzed vinylic hydrogen substitution reactions with aryl, benzyl, and styryl halides. J. Org. Chem., 1972, 37, 2320-2322.

4. Le Bras, J.; Muzart, J. Intermolecular dehydrogenative Heck reactions. Chem. Rev., 2011, 111, $1170-1214$.

5. Ferreira, E.M.; Zhang, H.; Stoltz, B.M. C-H bond functionalizations with palladium(II): intramolecular oxidative annulations of arenes. Tetrahedron, 2008, 64, 5987-6001.

6. Le Bras, J.; Muzart, J. Pd-catalyzed intermolecular dehydrogenative Heck reactions of five membered heteroarenes. Catalysts, 2020, 10, 571 (48 pages).

7. For more general reviews reported over the period and containing examples, see: (a) Yeung, C.S.; Dong, V.M. Catalytic dehydrogenative cross-coupling: forming carbon-carbon bonds by oxidizing two carbonhydrogen bonds. Chem. Rev., 2011, 111, 1215-1292; (b) Liu, C.; Zhang, H.; Shi, W.; Lei, A. Bond formations between two nucleophiles: transition metal catalyzed oxidative cross-coupling reactions. Chem. Rev., 2011, 111, 1780-1824; (c) Wu, Y.; Wang, J.; Mao, F.; Kwong, F.Y. Palladium-catalyzed cross- 
dehydrogenative functionalization of $\mathrm{C}\left(\mathrm{sp}^{2}\right)$-H bonds. Chem. Asian J., 2014, 9, 26-47; (d) Iwai, T.; Sawamura, M. Transition-metal-catalyzed site-selective $\mathrm{C}-\mathrm{H}$ functionalization of quinolines beyond $\mathrm{C} 2$ selectivity. ACS Catal., 2015, 5, 5031-5040; (e) Ma, W.; Gandeepan, P.; Lid, J.; Ackermann, L. Recent advances in positional-selective alkenylations: removable guidance for twofold C-H activation. Org. Chem. Front. 2017, 4, 1435-1467; (f) Koubachi, J.; Brahmi, N.E.; Guillaumet, G.; Kazzouli, S.E. Oxidative alkenylation of fused bicyclic heterocycles. Eur. J. Org. Chem., 2019, 2568-2586; (g) Tiwari, V.K.; Kapur, M. Catalyst-controlled positional-selectivity in C-H functionalizations. Org. Biomol. Chem., 2019, 17, 1007-1026; (h) Biswas, A.; Maity, S.; Pan, S.; Samanta, R. Transition metal-catalysed direct C-H bond functionalizations of 2-pyridone beyond C3-selectivity. Chem Asian J., 2020, 15, 2092-2109; (i) Yun, Y.-1.; Yang, J.; Miao, Y.-h.; Sun, J.; Wang, X.-j. Recent advances in palladium(II)-catalyzed activation of aromatic ring C-H bonds. J. Saudi Chem. Soc., 2020, 24, 151-185.

8. For examples, see: Zhang, Z.; Tanakai, K.; Yu, J.-Q. Remote site-selective C-H activation directed by a catalytic bifunctional template. Nature, 2017, 543, 538-542.

9. For examples, see: (a) Gong, X.; Song, G.; Zhang, H.; Li, X. Palladium-catalyzed oxidative cross-coupling between pyridine $N$-oxides and indoles. Org. Lett., 2011, 13, 1766-1769; (b) Kianmehr, E.; Torabi, M.; Khalkhali, M.R.; Faghih, N.; Khan, K.M. Palladium- catalyzed regioselective cross- dehydrogenative coupling of benzofurans with uracils at room temperature. Eur. J. Org. Chem., 2015, 2796-2800.

10. Broggini, G.; Beccalli, E.M.; Fasana, A.; Gazzola, S. Palladium-catalyzed dual C-H or N-H functionalization of unfunctionalized indole derivatives with alkenes and arenes. Beilstein J. Org. Chem., 2012, 8, 1730-1746.

11. (a) Thiery, E.; Harakat, D.; Le Bras, J.; Muzart, J. Pd-catalyzed oxidative coupling of alkylfurans with olefins through C-H activation: synthesis of difurylalkanes. Organometallics, 2008, 27, 3996-4004; (b) Vasseur, A.; Harakat, D.; Muzart, J.; Le Bras, J. ESI-MS studies of the dehydrogenative Heck reaction of furans with acrylates using benzoquinone as the reoxidant and DMSO as the solvent. J. Org. Chem., 2012, 77, 5751-5758; (c) Vasseur, A.; Harakat, D.; Muzart, J.; Le Bras, J. Aerobic dehydrogenative Heck reactions of heterocycles with styrenes: a negative effect of metallic co-oxidants. Adv. Synth. Catal., 2013, 355, 59-67; (d) Rauf, W.; Brown, J.M. Reactive intermediates in catalytic alkenylation; pathways for Mizoroki-Heck, oxidative Heck and Fujiwara-Moritani reactions. Chem. Commun., 2013, 49, 8430-8440; (e) Vasseur, A.; Laugel, C.; Harakat, D.; Muzart, J.; Le Bras, J. Ligand-promoted reactivity of alkenes in dehydrogenative Heck reactions of furans and thiophenes. Eur. J. Org. Chem., 2015, 944-948; (f) Jia, K.Y.; Yu, J.-B.; Jiang, Z.-J.; Su, W.-K. Mechanochemically activated oxidative coupling of indoles with acrylates through $\mathrm{C}-\mathrm{H}$ activation: synthesis of 3 -vinylindoles and $\beta, \beta$-diindolyl propionates and study of the mechanism. J. Org. Chem., 2016, 81, 6049-6055; (g) Jones, R.C. Controlling reactivity in the FujiwaraMoritani reaction: examining solvent effects and the addition of 1,3-dicarbonyl ligands on the oxidative coupling of electron rich arenes and acrylates. Tetrahedron Lett., 2020, 61, 151471.

12. Hu, H.; Liu, Y.; Zhong, H.; Zhu, Y.; Wang, C.; Ji, M. Heck-type cross-dehydrogenative coupling reactions of indolizines at the 3-position with electron-deficient alkenes through palladium-catalyzed C-H activation. Chem. Asian J., 2012, 7, 884-888.

13. Ye, M.; Gao, G.-L.; Yu, J.-Q. Ligand-promoted C-3 selective C-H olefination of pyridines with Pd catalysts. J. Am. Chem. Soc., 2011, 133, 6964-6967.

14. Maes, J.; Maes, B.U.W. A journey through metal-catalyzed C-H functionalization of heterocycles: insights and trends. Adv. Heterocycl. Chem., 2016, 120, 137-194.

15. Petit, A.; Flygare, J.; Miller, A.T.; Winkel, G.; Ess, D.H. Transition-state metal aryl bond stability determines regioselectivity in palladium acetate mediated $\mathrm{C}-\mathrm{H}$ bond activation of heteroarenes. Org. Lett., 2012, 14, 3680-3683.

16. Zhao, J.; Huang, L.; Cheng, K.; Zhang, Y. Palladium-catalyzed alkenation of thiophenes and furans by regioselective C-H bond functionalization. Tetrahedron Lett., 2009, 50, 2758-2761.

17. Yang, Y.; Cheng, K.; Zhang, Y. Highly regioselective palladium-catalyzed oxidative coupling of indolizines and vinylarenes via C-H bond cleavage. Org. Lett., 2009, 11, 5606-5609.

18. Wen, P.; Li, Y.; Zhou, K.; Ma, C.; Lan, X.; Ma, C.; Huang, G. Palladium-catalyzed C-2 selective C-H olefination of pyridines. Adv. Synth. Catal., 2012, 354, 2135-2140.

19. Kim, D.; Hong, S. Palladium(II)-catalyzed direct intermolecular alkenylation of chromones. Org. Lett., 2011, 13, 4466-4469. 
20. Lv, J.; Liang, Y.; He, P.; Cai, Z.; Liu, J.; Huang, F. Palladium-catalyzed direct alkenylation of 2-methyl$4 H$-pyrido[1,2-a]pyrimidin-4-ones using oxygen as the oxidant. RSC Adv., 2015, 5, 36171-36174.

21. For discussions on trans-effect, see: (a) Quagliano, J.V.; Schubert, L. The "trans" effect in complex inorganic compounds. Chem. Rev., 1952, 50, 201-260; (b) Coe, B.J.; Glenwright, S.J. Trans-effects in octahedral transition metal complexes. Coord. Chem. Rev., 2000, 203, 5-80.

22. Engle, K.M.; Yu, J.-Q. Developing ligands for palladium(II)-catalyzed C-H functionalization: intimate dialogue between ligand and substrate. J. Org. Chem., 2013, 78, 8927-8955.

23. Cong, X.; Tang, H.; Wu, C.; Zeng, X. Role of mono-N-protected amino acid ligands in palladium(II)catalyzed dehydrogenative Heck reactions of electron-deficient (hetero)arenes: experimental and computational studies. Organometallics, 2013, 32, 6565-6575.

24. Bhaskararao, B.; Singh, S.; Anand, M.; Verma, P.; Prakash, P.; Athira, C.; Malakar, S.; Schaefer, H.F.; Sunoj, R.B. Is silver a mere terminal oxidant in palladium catalyzed $\mathrm{C}-\mathrm{H}$ bond activation reactions? Chemical Science, 2020, 11, 208-216.

25. Davies, D.L.; Macgregor, S.A.; McMullin, C.L. Computational studies of carboxylate-assisted C-H activation and functionalization at group 8-10 transition metal centers. Chem. Rev., 2017, 117, 8649-8709.

26. (a) Muzart, J.; Pète, J.-P. Dehydrogenation of cyclohexanones catalyzed by palladium II trifluoroacetate. J. Mol. Catal., 1982, 15, 373-376; (b) Gligorich, K.M.; Sigman, M.S. Mechanistic questions about the reaction of molecular oxygen with palladium in oxidase catalysis. Angew. Chem. Int. Ed., 2006, 118, 66126615; (c) Muzart, J. Molecular oxygen to regenerate $\mathrm{Pd}^{\mathrm{II}}$ active species. Chem. Asian J., 2006, 1, 508-515; (d) Gligorich, K.M.; Sigman, M.S. Recent advancements and challenges of palladium ${ }^{\text {II }}$-catalyzed oxidation reactions with molecular oxygen as the sole oxidant. Chem. Commun., 2009, 3854-3867; (e) Keith, J.M.; Muller, R.P.; Kemp, R.A.; Goldberg, K.I.; Goddard, III, W.A.; Oxgaard, J. Mechanism of direct molecular oxygen insertion in a palladium(II)-hydride bond. Inorg. Chem., 2006, 45, 9631-9633; (f) Chowdhury, S.; Rivalta, I.; Russo, N.; Sicilia, E. Theoretical investigation of the mechanism of acid-catalyzed oxygenation of a Pd(II)-hydride to produce a Pd(II)-hydroperoxide. J. Chem. Theory Comput., 2008, 4, 1283-1292.

27. Keith, J.M.; Goddard, W.A., III; Oxgaard, J. Pd-Mediated activation of molecular oxygen: $\operatorname{Pd}(0)$ versus direct insertion J. Am. Chem. Soc. 2007, 129, 10361-10369; (b) Konnick, M.M.; Stahl, S.S. Reaction of molecular oxygen with a $\mathrm{Pd}^{\mathrm{II}}$-hydride to produce a $\mathrm{Pd}^{\mathrm{II}}$-hydroperoxide: experimental evidence for an $\mathrm{HX}$ reductive-elimination pathway. J. Am. Chem. Soc., 2008, 130, 5753-5762; (c) Decharin, N.; Popp, B.V.; Stahl, S.S. Reaction of $\mathrm{O}_{2}$ with [(-)-Sparteine]Pd(H)Cl: evidence for an intramolecular [H-L] "reductive elimination" pathway. J. Am. Chem. Soc., 2011, 133, 13268-13271.

28. (a) Popp, B.V.; Stahl, S.S. Mechanism of $\mathrm{Pd}(\mathrm{OAc})_{2} /$ pyridine catalyst reoxidation by $\mathrm{O}_{2}$ : influence of labile monodentate ligands and identification of a biomimetic mechanism for $\mathrm{O}_{2}$ activation. Chem. Eur. J., 2009, 15, 2915-2922; (b) Keith, J.M.; Goddard, III, W. A. Mechanism for activation of molecular oxygen by cisand trans-(pyridine $)_{2} \mathrm{Pd}(\mathrm{OAc}) \mathrm{H}: \mathrm{Pd}(0)$ versus direct insertion. J .Am. Chem. Soc., 2009, 131, 1416-1425; (c) Konnick, M.M.; Decharin, N.; Popp, B.V.; Stahl, S.S. $\mathrm{O}_{2}$ insertion into a palladium(II)-hydride bond: observation of mechanistic crossover between HX-reductive elimination and hydrogen-atom-abstraction pathways. Chem. Sci., 2011, 2, 326-330.

29. Bedford, R. B.; Bowen, J. G.; Davidson, R. B.; Haddow, M. F.; Seymour-Julen, A. E.; Sparkes, H. A.; Webster, R. L. Facile hydrolysis and alcoholysis of palladium acetate. Angew. Chem., Int. Ed., 2015, 54, 6591-6594.

30. Petit, A.; Flygare, J.; Miller, A.T.; Winkel, G.; Ess, D.H. Transition-state metal aryl bond stability determines regioselectivity in palladium acetate mediated $\mathrm{C}-\mathrm{H}$ bond activation of heteroarenes. Org. Lett., 2012, 14, 3680-3683.

31. Gorelsky, S.I. Tuning the Regioselectivity of palladium-catalyzed direct arylation of azoles by metal coordination. Organometallics, 2012, 31, 794-797.

32. Ye, M.; Gao, G.-L.; Edmunds, A.J.F.; Worthington, P.A.; Morris, J.A.; Yu, J.-Q. Ligand-promoted C3selective arylation of pyridines with Pd catalysts: gram-scale synthesis of ( \pm )-Preclamol. J. Am. Chem. Soc., 2011, 133, 19090-19093.

33. Davies, D.L.; Donald, S.M.A.; Macgregor, S.A. Computational study of the mechanism of cyclometalation by palladium acetate. J. Am. Chem. Soc., 2005, 127, 13754-13755.

34. Muzart, J. N,N-Dimethylformamide: much more than a solvent. Tetrahedron, 2009, 65, 8313-8323. 
35. (a) Gutmann, V.; Resch, G.; Linert, W. Structural variability in solutions. Coord. Chem. Rev., 1982, 43, 133-164; (b) Díaz, C.; Yutronic, N. Coordinating properties of some solvents towards the fragment $\mathrm{CpFe}(\mathrm{dppe})^{+}$. Polyhedron, 1996, 15, 997-1001.

36. Kravtsova, S.V.; Romm, I.P.; Stash, A.I.; Belsky, V.K. Bis(acetato- $O$ )bis(pyridine- $N$ )palladium(II) monohydrate and bis(acetato- $O$ )bis(diethylamine- $N$ )palladium(II). Acta Crystallogr., 1996, C52, 22012204.

37. Zhang, Y.-H.; Shi, B.-F.; Yu, J.-Q. Pd(II)-catalyzed olefination of electron-deficient arenes using 2,6dialkylpyridine ligands. J. Am. Chem. Soc., 2009, 131, 5072-5074.

38. Skapski, A.C.; Smart, M.L. The crystal structure of trimeric palladium(II) acetate. J. Chem. Soc, Chem. Commun., 1970, 658-659.

39. Kurzeev, S.A.; Kazankov, G.M.; Ryabov, A.D. Second- and inverse order pathways in the mechanism of orthopalladation of primary amines. Inorg. Chim. Acta, 2002, 340, 192-196.

40. Aouf, C.; Thiery, E.; Le Bras, J.; Muzart, J. Palladium-catalyzed dehydrogenative coupling of furans with styrenes. Org. Lett., 2009, 11, 4096-4099.

41. (a) Adrio, L.A.; Nguyen, B.N.; Guilera, G.; Livingston, A.G.; Hii, K.K. Speciation of $\operatorname{Pd}(\mathrm{OAc})_{2}$ in ligandless Suzuki-Miyaura reactions. Catal. Sci. Technol., 2012, 2, 316-323; (b) Zhang, D.; Yang, D.; Wang, S.; Zeng, L.; Xin, J.; Zhang, H.; Lei, A. The real structure of $\mathrm{Pd}(\mathrm{OAc})_{2}$ in various solvents. Chin. J. Chem., 2021, 39, 307-311.

42. For C-H bond activation mediated by mono-, bi- and trinuclear palladium complexes, see: (a) Váňa, J.; Lang, J.; Šoltésová, M.; Hanusek, J.; Růžička, A.; Sedlák, M.; Roithová, J. The role of trinuclear species in a palladium acetate/trifluoroacetic acid catalytic system. Dalton Trans., 2017, 46, 16269-16275; (b) Váňa, J.; Hanusek, J.; Sedlák, M. Bi and trinuclear complexes in palladium carboxylate-assisted C-H activation reactions. Dalton Trans., 2018, 47, 1378-1382; (c) Prendergast, A.M.; Zhang, Z.; Lin, Z.; McGlacken, G.P. Mechanistic studies on the palladium-catalyzed cross-dehydrogenative coupling of 4-phenoxy-2coumarins: experimental and computational insights. Dalton Trans., 2018, 47, 6049-6053; (d) Zhang, L.-L.; Zhang, L.; Li, S.-J.; Fang, D.-C. DFT studies on the distinct mechanisms of C-H activation and oxidation reactions mediated by mononuclear- and binuclear-palladium. Dalton Trans., 2018, 47, 6102-6111.

43. For calculations on the $\mathrm{C}-\mathrm{H}$ bond activation depending on the nature of carboxylic acids, see: Granell, J.; Martínez, M. Kinetico-mechanistic studies of cyclometalating C-H bond activation reactions on $\mathrm{Pd}(\mathrm{II})$ and $\mathrm{Rh}(\mathrm{II})$ centres: the importance of non-innocent acidic solvents in the process. Dalton Trans., 2012, 41, 11243-11258.

44. Mueller, J.A.; Goller, C.P.; Sigman, M.S. Elucidating the significance of $\beta$-hydride elimination and the dynamic role of acid/base chemistry in a palladium-catalyzed Aerobic Oxidation of Alcohols. J. Am. Chem.4Soc., 2004, 126, 9724 -9734.

45. (a) Lafrance, M.; Fagnou, K. Palladium-catalyzed benzene arylation: incorporation of catalytic pivalic acid as a proton shuttle and a key element in catalyst design. J. Am. Chem. Soc., 2006, 128, 16496-16497; (b) Lafrance, M.; Gorelsky, S.I.; Fagnou, K. High-yielding palladium-catalyzed intramolecular alkane arylation: reaction development and mechanistic studies. J. Am. Chem. Soc., 2007, 129, 14570-14751; (c). Lafrance, M.; Lapointe, D.; Fagnou, K. Mild and efficient palladium-catalyzed intramolecular direct arylation reactions. Tetrahedron, 2008, 64, 6015-6020.

46. Ackermann, L. Carboxylate-assisted transition-metal-catalyzed C-H bond functionalizations: mechanism and scope. Chem. Rev., 2011, 111, 1315-1345.

47. Lapointe, D.; Fagnou, K. Overview of the mechanistic work on the concerted metallation-deprotonation pathway. Chem. Lett., 2010, 39, 1118-1126.

48. Haines, B.E.; Berry, J.F.; Yu, J.-Q.; Musaev, D.G. Factors controlling stability and reactivity of dimeric $\mathrm{Pd}(\mathrm{II})$ complexes in C-H functionalization catalysis. ACS Catal., 2016, 6, 829-839.

49. Clemenceau, A.; Thesmar, P.; Gicquel, M.; Le Flohic, A.; Baudoin, O. Direct synthesis of cyclopropanes from gem-dialkyl groups through double C-H activation. J. Am. Chem. Soc. 2020, 142, 15355-15361.

50. (a) Yang, Y.-F.; Cheng, G.-J.; Liu, P.; Leow, D.; Sun, T.-Y.; Chen, P.; Zhang, X.; Yu, J.-Q.; Wu, Y.-D.; Houk, K.N. Palladium-catalyzed meta-selective C-H bond activation with a nitrile-containing template: computational study on mechanism and origins of selectivity, J. Am. Chem. Soc., 2014, 136, 344-355; (b) Anand, M.; Sunoj, R.B.; Schaefer III, H.F. Non-innocent additives in a palladium(II)-catalyzed C-H bond activation reaction: insights into multimetallic active catalysts, J. Am. Chem. Soc., 2014, 136, 5535-5538; 
(c) Fang, L.; Saint-Denis, T.G.; Taylor, B.L.H.; Ahlquist, S.; Hong, K.; Liu, S.; Han, L.; Houk, K.N.; Yu, J.-Q. Experimental and computational development of a conformationally flexible template for the meta-CH functionalization of benzoic acids. J. Am. Chem. Soc., 2017, 139, 10702-10714; (d) Xu, X.; Chen, K. Palladium-catalyzed $\mathrm{C}-\mathrm{H}$ activation of anisole with electron-deficient auxiliary ligands: a mechanistic investigation. Org. Biomol. Chem., 2020, 18, 5857-5866.

51. Shang, Y.; Jie, X.; Zhou, J.; Hu, P.; Huang, S.; Su, W. Pd-catalyzed C-H olefination of (hetero)arenes by using saturated ketones as an olefin source. Angew. Chem. Int. Ed., 2013, 52, 1299-1303.

52. Le Bras, J.; Muzart, J. Pd-catalyzed domino dehydrogenation/Heck-type reactions of carbonyl compounds. Adv. Synth. Catal., 2018, 360, 2411-2428.

53. (a) Muzart, J. One-pot synthesis of $\alpha, \beta$-unsaturated carbonyl compounds through palladium-mediated dehydrogenation of ketones, aldehydes, esters, lactones and amides. Eur. J. Org. Chem., 2010, 3779-3790; (b) Le Bras, J.; Muzart, J. The Saegusa oxidation and related procedures. In Organic Reactions, Denmark, S.E. et al. Eds, Vol. 98, 2019, pp 1-172, J. Wiley, Hoboken.

54. Chen, Y.; Wang, F.; Jia, A.; Li, X. Palladium-catalyzed selective oxidative olefination and arylation of 2pyridones. Chem. Sci., 2012, 3, 3231-3236.

55. Bouquillon, S.; Muzart, J. Palladium(0)-catalyzed isomerization of (Z)-1,4-diacetoxy-2-butene: dependence of $\eta^{1}$ - or $\eta^{3}$-allylpalladium as a key intermediate on the solvent polarity. Eur. J. Org. Chem., 2001, 33013305.

56. (a) Bäckvall, J.-E., Hopkins, R.B.; Grennberg, H.; Mader, M.; Awasthi, A.K. Multistep electron transfer in palladium-catalyzed aerobic oxidations via a metal macrocycle-quinone system. J. Am. Chem. Soc., 1990, 112, 5160-5166; (b) Piera, J.; Bäckvall, J.-E. Catalytic oxidation of organic substrates by molecular oxygen and hydrogen peroxide by multistep electron transfer - A biomimetic approach. Angew. Chem. Int. Ed., 2008, 47, 3506-3523.

57. Gigant, N.; Bäckvall, J.-E. Synthesis of conjugated dienes via a biomimetic aerobic oxidative coupling of two $\mathrm{C}_{\text {vinyl }}-\mathrm{H}$ bonds. Chem. Eur. J., 2013, 19, 10799-10803.

58. (a) Hegedus, L.S.; Allen, G.F.; Bozell, J.J.; Waterman, E.L. Palladium-assisted intramolecular amination of olefins. Synthesis of nitrogen heterocycles. J. Am. Chem. Soc. 1978, 100, 5800-5807; (b) A. Heumann, B. Akermark, Oxidation with palladium salts: catalytic preparation of ally1 acetates from monoolefins using a three-component oxidation system. Angew. Chem. Int. Ed. Engl. 1984, 23, 453-454; (c) Bäckvall, J.-E.; Bystrom, S.E.; Nordberg, R.E. Stereo- and regioselective palladium-catalyzed 1,4-diacetoxylation of 1,3dienes. J. Org. Chem. 1984, 49, 4619-4631; (d) Nahra, F.; Liron, F.; Prestat, G.; Mealli, C.; Messaoudi, A.; Poli, G. Striking AcOH acceleration in direct intramolecular allylic amination reactions. Chem. Eur. J. 2009, 15, 11078-11082.

59. (a) Grennberg, H.; Gogoll, A.; Bäckvall, J.-E. Acid-induced transformation of palladium(0)-benzoquinone complexes to palladium(II) and hydroquinone. Organometallics 1993, 12, 1790-1793; (b) Vasseur, A.; Muzart, J.; Le Bras, J. Ubiquitous benzoquinones, multitalented compounds for palladium-catalyzed oxidative reactions. Eur. J. Org. Chem., 2015, 4053-4059; (c) Mulligan, C.J.; Parker, J.S.; Hii, K.K. Revisiting the mechanism of the Fujiwara-Moritani reaction. React. Chem. Eng., 2020, 5, 1104-1111.

60. Lah, H.U.; Rasool, F.; Yousuf, S.K. Palladium catalyzed $\mathrm{C}\left(\mathrm{sp}^{2}\right)-\mathrm{C}\left(\mathrm{sp}^{2}\right)$ bond formation. A highly regio- and chemoselective oxidative Heck C-3 alkenylation of pyrones and pyridones. RSC Adv., 2015, 5, 7895878961.

61. Katsina, T.; Anagnostaki, E.E.; Mitsa, F.; Sarli, V.; Zografos, A.L. Palladium-catalyzed direct alkenylation of 4-hydroxy-2-pyridones. RSC Adv., 2016, 6, 6978-6982.

62. Fristup, P.; Le Quement, S.; Tanner, D.; Norrby, P.-O. Reactivity and regioselectivity in the Heck reaction: Hammett study of 4-substituted styrenes. Organometallics, 2004, 23, 6160-6165.

63. Jutand, A. Mechanisms of the Mizoroki-Heck reaction. In The Mizoroki-Heck Reaction Oestreich, M. Ed., Wiley: Chichester, 2009, pp 1-50.

64. Wucher, P.; Caporaso, L.; Roesle, P.; Ragone, F.; Cavallo, L.; Macking, S.; Göttker-Schnetmann, I. Breaking the regioselectivity rule for acrylate insertion in the Mizoroki-Heck reaction. Proc. Natl. Acad. Sci. U. S. A., 2011, 108, 8955-8959.

65. Zhang, G.; Li, Z.; Huang, Y.; Xu, J.; Wu, X.; Yao, H. Direct C3-alkenylation of pyridin-4(1H)-one via oxidative Heck coupling. Tetrahedron, 2013, 69, 1115-1119. 
66. Li, M.; Li, L.; Ge, H. Direct C-3-alkenylation of quinolones via palladium-catalyzed C-H functionalization. Adv. Synth. Catal., 2010, 352, 2445-2449.

67. Balcells, D.; Clot, E.; Eisenstein, O. C-H bond activation in transition metal species from a computational perspective. Chem. Rev. 2010, 110, 749-823.

68. Cao, L.; Kabeshov, M.; Ley, S.V.; Lapkin, A.A. In silico rationalisation of selectivity and reactivity in Pdcatalysed C-H activation reactions. Beilstein J. Org. Chem., 2020, 16, 1465-1475.

69. Guo, T.; Liu, Y.; Zhao, Y.-H.; Zhang, P.-K.; Han, S.-L.; Liu, H.M. Palladium-catalyzed external-oxidantfree coupling reactions between isoquinoline/quinoline $N$-oxides with olefins. Tetrahedron Lett., 2016, 57 , 3920-3923.

70. Moon, Y.; Kwon, D.; Hong, S. Palladium-catalyzed dehydrogenation/oxidative cross-coupling sequence of $\beta$-heteroatom-substituted ketones. Angew. Chem. Int. Ed., 2012, 51, 11333-11336.

71. Min, M.; Kima, Y.; Hong, S. Regioselective palladium-catalyzed olefination of coumarins via aerobic oxidative Heck reactions. Chem. Commun., 2013, 49, 196-198.

72. Ortiz-de-Elguea, V.; Sotomayor, N.; Lete, E. Two consecutive palladium(II)-promoted C-H alkenylation reactions for the synthesis of 3-alkenylquinolones. Adv. Synth. Catal., 2015, 357, 463-473.

73. (a) Yan, G.; Borah, A.J.; Yang, M. Recent advances in catalytic functionalization of $N$-oxide compounds via C-H bond activation. Adv. Synth. Catal., 2014, 356, 2375-2394; (b) Wang, D.; Désaubry, L.; Li, G.; Huang, M.; Zheng, S. Recent advances in the synthesis of C2-functionalized pyridines and quinolines using $N$-oxide chemistry. Adv. Synth. Catal., 2021, 363, 2-39.

74. Roudesly, F.; Veiros, L.F.; Oble, J.; Poli, G. Pd-catalyzed direct C-H alkenylation and allylation of azine $N^{-}$oxides. Org. Lett., 2018, 20, 2346-2350.

75. Zhang, L.; Fang, D.-C. An explicit interpretation of the directing group eff ect for the $\mathrm{Pd}(\mathrm{OAc})_{2}{ }^{-}$catalyzed aromatic C-H activations. J. Org. Chem., 2016, 81, 7400-7410.

76. Wu, J.; Cui, X.; Chen, L.; Jiang, G.; Wu, Y. Palladium-catalyzed alkenylation of quinoline- $N$-oxides via C$\mathrm{H}$ activation under external-oxidant-free conditions. J. Am. Chem. Soc., 2009, 131, 13888-13889.

77. Cu-catalyzed DHR-type of quinoline $N$-oxides with styrenes has been recently reported: Hu, H.; Hu, X.; Liu, Y. Copper-catalyzed ortho-functionalization of quinoline $N$-oxides with vinyl arenes. Angew. Chem. Int. Ed., 2020, 59, 18975-18979.

78. Pool, J.A; Scott, B.L.; Kiplinger, J.L. A new mode of reactivity for pyridine $N$-oxide: C-H activation with uranium(IV) and thorium(IV) bis(alkyl) complexes. J. Am. Chem. Soc., 2005, 127, 1338-1339.

79. Zhang, L.; Jiang, B.; Zhou, J.; Yu, L.; Chen, Y. Preferred C2-H activation of quinoline $N$ - oxides catalyzed by palladium acetate: DFT study on the plausible mechanism and regioselectivity. ChemistrySelect, 2018, 3, 11469-11475.

80. Stephens, D.E.; Lakey-Beitia, J.; Atesin, A.C.; Ateşin, T.A.; Chavez, G.; Arman, H.D.; Larionov, O.V. Palladium-catalyzed $\mathrm{C} 8$-selective $\mathrm{C}$-H arylation of quinoline $\mathrm{N}$-oxides: insights into the electronic, steric, and solvation effects on the site selectivity by mechanistic and DFT computational studies. ACS Catal., 2015, 5, 167-175.

81. Sciosci, D.; Valentini, F.; Ferlin, F.; Chen, S.; Gu, Y.; Piermatti, O.; Vaccaro, L. A heterogeneous and recoverable palladium catalyst to access the regioselective $\mathrm{C}-\mathrm{H}$ alkenylation of quinoline $\mathrm{N}$-oxides. Green Chem., 2020, 22, 6560-6566.

82. Chen, X.; Cui, X.; Wu, Y. "One-Pot" approach to 8- acylated 2- quinolinones via palladium-catalyzed regioselective acylation of quinoline $N^{-}$oxides. Org. Lett., 2016, 18, 2411-2414.

83. Moon, Y.; Hong, S. A facile route to isoflavonequinones via the direct cross-coupling of chromones and quinones. Chem. Commun., 2012, 48, 7191-7193.

84. Kim, Y.; Moon, Y.; Kang, D.; Hong, S. Synthesis of heterocyclic-fused benzopyrans via the Pd(II)catalyzed C-H alkenylation/C-O cyclization of flavones and coumarins. Org. Biomol. Chem., 2014, 12, 3413-3422.

85. Tan, X.-c.: Zhao, H.-y.; Pan, Y.-m.; Wu, N.; Wang, H.-s.; Chen, Z.-f. Atom-economical chemoselective synthesis of furocoumarins via cascade palladium catalyzed oxidative alkoxylation of 4oxohydrocoumarins and alkenes. RSC Adv., 2015, 5, 4972-4975.

86. Chen, H.; Farizyan, M.; Ghiringhelli, F.; van Gemmeren, M. Sterically controlled C-H olefination of heteroarenes. Angew. Chem. Int. Ed., 2020, 59, 12213-12220. 
87. Das, A.; Jana, A.; Maji, B. Palladium-catalyzed remote C-H functionalization of 2-aminopyrimidines. Chem. Commun., 2020, 56, 4284-4287.

88. Liu, W.; Wang, S.; Zhang, Q.; Yu, J.; Li, J.; Xie, Z.; Cao, H. Regioselective C3 alkenylation of $4 \mathrm{H}$ pyrido[1,2-a]pyrimidin-4-ones via palladium-catalyzed C H activation. Chem. Asian J., 2014, 9, 24362439.

89. Yu, Y.-Y.; Georg, G.I. Dehydrogenative alkenylation of uracils via palladium-catalyzed regioselective C-H activation. Chem. Commun., 2013, 49, 3694-3696.

90. Cirujano, F.G.; Leo, P.; Vercammen, J.; Smolders, S.; Orcajo, G.; De Vos, D.E. MOFs extend the lifetime of Pd(II) catalyst for room temperature alkenylation of enamine- like arenes. Adv. Synth. Catal., 2018, 360, 3872-3876.

91. Cho, S.H.; Hwang, S.J.; Chang, S. Palladium-catalyzed C-H functionalization of pyridine $N$-oxides: highly selective alkenylation and direct arylation with unactivated arenes. J Am. Chem. Soc., 2008, 130, 92549256.

92. Franco, M.S.F.; Paula, M.H.; Glowacka, P.C.; Fumagalli, F.; Clososki, G.C.; Emery, F.S. Palladiumcatalyzed $\mathrm{C}-\mathrm{H}$ alkenylation of quinoxaline $\mathrm{N}$-oxide enabled by a mono- $\mathrm{N}$-protected amino acid. Tetrahedron Lett., 2018, 59, 2562-2566.

93. (a) Gigant, N.; Gillaizeau, I. Palladium(II)-catalyzed direct alkenylation of nonaromatic enamides. Org. Lett., 2012, 14, 3304-3307; (b) Gigant, N.; Chausset-Boissarie, L.; Rey-Rodriguez, R.; Gillaizeau, I. Direct alkenylation of non-aromatic enamides via palladium-catalyzed oxidative coupling: synthetic developments and applications. C. R. Chim., 2013, 16, 358-362.

94. Kang, D.; Cho, J.; Lee, P.H. Palladium-catalyzed direct C-3 oxidative alkenylation of phosphachromones. Chem. Commun., 2013, 49, 10501-10503.

95. Kim, C.-E.; Son, J.-Y.; Shin, S.; Seo, B.; Lee, P.H. Alkenylation of phosphacoumarins via aerobic oxidative Heck reactions and their synthetic application to fluorescent benzophosphacoumarins. Org. Lett., 2015, 17, 908-911.

96. Kim, N.; Min, M.; Hong, S. Regioselective palladium(II)-catalyzed aerobic oxidative Heck-type C3 alkenylation of sulfocoumarins. Org. Chem. Front., 2015, 2, 1621-1624.

97. Kim, S.-T.; Baik, M.-H. Reductive activation of Pd ${ }^{\mathrm{II}}-$ precatalysts via decarboxylation of pivalate in direct $\mathrm{C}-\mathrm{H}$ arylation reactions. Chem. Commun., 2020, 56, 13868-13871. 